\title{
Impact of plants on the diversity and activity of methylotrophs in soil
}

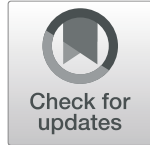

Michael C. Macey ${ }^{1,2}$, Jennifer Pratscher ${ }^{3}$, Andrew T. Crombie ${ }^{4}$ and J. Colin Murrell ${ }^{*}$

\begin{abstract}
Background: Methanol is the second most abundant volatile organic compound in the atmosphere, with the majority produced as a metabolic by-product during plant growth. There is a large disparity between the estimated amount of methanol produced by plants and the amount which escapes to the atmosphere. This may be due to utilisation of methanol by plant-associated methanol-consuming bacteria (methylotrophs). The use of molecular probes has previously been effective in characterising the diversity of methylotrophs within the environment. Here, we developed and applied molecular probes in combination with stable isotope probing to identify the diversity, abundance and activity of methylotrophs in bulk and in plant-associated soils.

Results: Application of probes for methanol dehydrogenase genes ( $m x a F, x o x F, m d h 2)$ in bulk and plant-associated soils revealed high levels of diversity of methylotrophic bacteria within the bulk soil, including Hyphomicrobium, Methylobacterium and members of the Comamonadaceae. The community of methylotrophic bacteria captured by this sequencing approach changed following plant growth. This shift in methylotrophic diversity was corroborated by identification of the active methylotrophs present in the soils by DNA stable isotope probing using ${ }^{13} \mathrm{C}$-labelled methanol. Sequencing of the $16 \mathrm{~S}$ rRNA genes and construction of metagenomes from the ${ }^{13} \mathrm{C}$-labelled DNA revealed members of the Methylophilaceae as highly abundant and active in all soils examined. There was greater diversity of active members of the Methylophilaceae and Comamonadaceae and of the genus Methylobacterium in plant-associated soils compared to the bulk soil. Incubating growing pea plants in a ${ }^{13} \mathrm{CO}_{2}$ atmosphere revealed that several genera of methylotrophs, as well as heterotrophic genera within the Actinomycetales, assimilated plant exudates in the pea rhizosphere.
\end{abstract}

Conclusion: In this study, we show that plant growth has a major impact on both the diversity and the activity of methanol-utilising methylotrophs in the soil environment, and thus, the study contributes significantly to efforts to balance the terrestrial methanol and carbon cycle.

Keywords: Methanol, Rhizosphere, Stable isotope probing, Methylotroph, Methanol dehydrogenase

\section{Introduction}

The large amount of carbon released to the soil via the roots of growing plants (1-20\% of total photosynthate [1]) has a profound impact on the microbial communities in soil [2]. Root exudates include organic acids, sugars, alcohols, mucilage, sloughed off cells and

\footnotetext{
* Correspondence: j.c.murrell@uea.ac.uk

${ }^{1}$ School of Environmental Sciences, University of East Anglia, Norwich Research Park, Norwich NR4 7TJ, UK

Full list of author information is available at the end of the article
}

methanol $[3,4]$. Growing and decaying plants account for the majority of methanol produced globally (149 Tg year $^{-1}$ ), released following demethylation of pectin in the walls of restructuring plant cells [5]. In the atmosphere, methanol is the second most abundant organic gas $(0.1-$ $10 \mathrm{ppb})$ after methane (1800 ppb) [6], but there is a large disparity between the estimated amount of methanol produced and the amount entering the atmosphere. This suggests that plant-associated methylotrophic microorganisms may be responsible for oxidation of a 
substantial proportion of the methanol produced by plants before it can escape to the atmosphere [7].

Methanol-oxidising methylotrophs can utilise methanol as a sole source of carbon and energy and are widespread in the terrestrial environment [7]. Methylotrophs detected in soil environments in previous studies typically belong to the Proteobacteria, although others, including Verrucomicrobia, Firmicutes, Flavobacterium and Actinobacteria, have also been detected [8-11]. Previous studies have indicated that methylotrophic bacteria are enriched in the rhizosphere of certain plant species, for example, Methylobacteraceae and Hyphomicrobiaceae in the rhizosphere of Arabidopsis thaliana [12], Methylophilaceae and Comamonadaceae in the pea rhizosphere and Methylophilaceae and Methylocaldum in the wheat rhizosphere [13]. Methanol dehydrogenase genes have been detected in the rhizosphere of rice, grasses, soybeans, cereals and pea plants [14-16], methanol dehydrogenase enzymes have been detected in the rhizosphere soils of oat, wheat and A. thaliana [17], and soils in association with $A$. thaliana had higher rates of methanol dissimilation than non-plantassociated soils [18]. However, the reasons for changes in the abundance of methylotrophs in the soil in response to plant growth are hard to identify, since many of these methylotrophs can also use multi-carbon compounds, which could be supplied either directly from the plant or from the exudate-induced accelerated breakdown of recalcitrant soil organic matter (SOM) [19].

The oxidation of methanol to formaldehyde requires the enzyme methanol dehydrogenase. There are several methanol dehydrogenases that have been characterised in different classes of methylotrophic organisms, and the most well characterised is the canonical MxaFI [20]. This enzyme is heterotetrameric in structure, with mxaF and mxaI encoding the large and small subunits respectively [21]. The large subunit contains a pyrroloquinoline quinone (PQQ) cofactor and a calcium ion [20, 21]. The function and expression of this methanol dehydrogenase in Methylobacterium extorquens AM1 requires 25 genes [22]. More recently, a lanthanide-dependent rather than calcium-dependent methanol dehydrogenase, XoxF, has been discovered [23]. Comparison of $x o x F$ genes in a range of methylotrophs showed that there are five distinct phylogenetic clades of $x o x F$, thus representing a considerable diversity of $x o x F$-dependent methanol dehydrogenases in bacteria [24]. The XoxF methanol dehydrogenase has a specific cytochrome $C_{L}$ and periplasmic solute binding protein associated with it, encoded by $x o x G$ and $x o x J$ respectively [23]. Mdh2 is a recently discovered divergent PQQ-methanol dehydrogenase, thus far identified in two genera of the Burkholderiales [25]. Sequence-based analysis of Mdh2 showed that it was closely related to type I alcohol dehydrogenases rather than a highly divergent $m x a F$ or $x o x F$ [25].
Most cultivation-independent studies investigating the diversity of methylotrophs in the terrestrial environment have used universal 16S rRNA gene sequencing, rather than analysis of methanol dehydrogenase genes. However, there are significant issues with the use of the $16 \mathrm{~S}$ rRNA gene to infer function, especially with methylotrophs. For example, only a few members of the genera Bacillus and Flavobacterium are methylotrophs [11, 26]. DNA-based diversity studies of methylotrophs therefore require use of a functional marker gene. Previous studies in the soil environment, using PCR primers targeting the large subunit encoding gene of the canonical methanol dehydrogenase, $m x a F[8]$, have revealed a relatively low diversity $[18,26,27]$, highlighting the necessity to incorporate the recently discovered novel MDH genes and enzymes, notably xoxF and $m d h 2$, into analyses of methylotrophs in soil. PCR primers targeting different clades of $x o x F$ are now available [28] but have not been extensively used in soil environments. To our knowledge, no PCR primers have been used to target the $m d h 2$ gene in soils. Another approach for characterising a specific metabolic guild within an environment is stable isotope probing (SIP), which tracks the incorporation of specific isotope-labelled substrates into target microbes [10]. A SIP-based approach to identify microbes actively utilising plant exudates in the rhizosphere involves incubating growing plants with ${ }^{13} \mathrm{CO}_{2}$ and then identifying ${ }^{13} \mathrm{C}$-labelled carbon in DNA extracted from the rhizosphere [29].

In this study, we aimed to examine the diversity of methanol utilisers, including those that may utilise the recently discovered MDHs XoxF and Mdh2, in the rhizosphere of two common crop plants, pea (Pisum sativum var. Avolar) and wheat (Triticum aestivum var. Paragon), and to verify that these methylotrophs used plant root exudates. Firstly, DNA-SIP with ${ }^{13} \mathrm{C}$-labelled methanol was used to identify methylotrophs in pea and wheat rhizosphere soil, and then ${ }^{13} \mathrm{CO}_{2}$ was used to follow the flow of plant-derived carbon into rhizosphere methylotrophs.

\section{Results and discussion}

Identification of methanol utilisers in rhizosphere soil Naturally grassed and unfertilised soil from Church Farm (a John Innes Centre site in Norfolk, UK) was used as the basis for this study. The soil from Church Farm was used to produce three experimental soils that were then analysed; pea and wheat plants were grown in containers in the laboratory, and the rhizosphere soils were collected at the reproductive stage of the life cycle of the pea and wheat plants, 4 weeks after planting, and compared with similarly treated but unplanted soil. DNA was extracted from the soils, and the microbial communities were analysed by $16 \mathrm{~S}$ 
rRNA gene and methanol dehydrogenase gene PCR amplicon sequencing, using either high-throughput methods (16S rRNA gene, $m x a F$, xoxF1, xoxF2, and $x o x F 5)$ or clone library analysis ( $m d h 2, x o x F 3)$.

Sequencing of $16 \mathrm{~S}$ rRNA genes from each habitat revealed that the most abundant phylum within the unplanted soil and the rhizosphere soils was the Proteobacteria (33\%), with Hyphomicrobiaceae (13\%) being the most abundant family within this phylum (Additional File 1). Actinobacteria and Planctomycetes were also abundant phyla (approximately 22 and 19\% relative abundance) within these soil environments. The $16 \mathrm{~S}$ rRNA gene sequencing identified genera that contain species previously known to oxidise and grow on methanol (extant methylotrophs) or that contain species that possess methanol dehydrogenase genes (putative methylotrophs) (Additional File 2). Thirty-four methylotrophic genera were identified in the 16S rRNA gene profile of the unplanted soil, at a combined relative abundance of $15.4 \%$, and 35 methylotrophic genera were distributed across pea and wheat rhizosphere soils, at $15.8 \%$ and $14.4 \%$ relative abundance respectively. The most abundant confirmed methylotrophic genera (Hyphomicrobium, Methylophilus and Verrucomicrobium) and putative methylotrophic genera (Flavobacterium and Bradyrhizobium) were found in all three habitats.
Amplification of mdh2 methanol dehydrogenase genes PCR primers for specific amplification of $m d h 2$ genes were designed by aligning $m d h 2$ gene sequences from the sequenced genomes of strains of Methylibium and Methyloversatilis as described in the "Methods" section. The specificity of the primers was assessed by performing PCR using DNA from mdh2-possessing bacteria, Methylibium sp. ROOT1272 and Methyloversatilis sp. LF1. Sequencing confirmed the identity of PCR products as $m d h 2$ methanol dehydrogenase genes. DNA from unplanted soil and pea rhizosphere soil did not yield PCR amplicons when assayed with the $m d h 2$ primers. However, when enriched with methanol (see the "DNA-SIP with 13C methanol" section), DNA extracted from pea rhizosphere soil yielded a PCR amplicon, and restriction fragment length polymorphism (RFLP) screening of the resultant clone library identified a single operational taxonomic unit (OTU), with a high degree of identity (96-99\% nucleotide identity) with $m d h 2$ sequences from Methyloversatilis (Fig. 1). The absence of mdh2 products in PCR assays with DNA from the soils that were not enriched with methanol, and the lack of sequence diversity in DNA from the methanol-enriched pea rhizosphere suggests that $m d h 2$ is not abundant in this environment, although it may be more relevant to other environments, such as in freshwater systems [31], where genera that possess $m d h 2$, including Methyloversatilis,

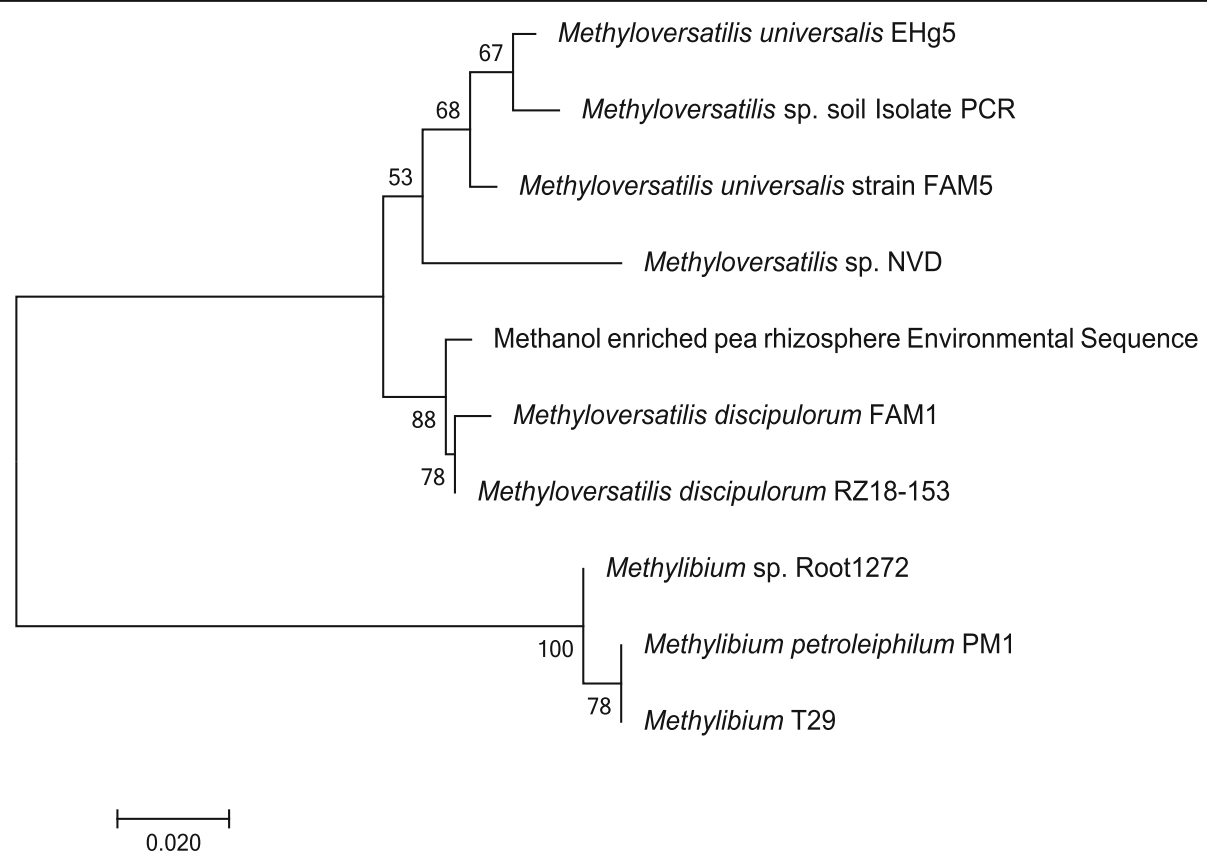

Fig. 1 Phylogeny of $m d h 2$ sequences retrieved from pea plant rhizosphere compared to $m d h 2$ from methylotrophic bacteria. Sequenced amplicons obtained from environmental DNA and DNA from cultures of methylotrophic bacteria are labelled as "Environmental Sequence" and "Isolate PCR" respectively. Full reference gene sequences were selected from the NCBI nucleotide database. The tree was drawn in Mega7 [30] using the neighbour-joining method. Scale bar indicates 0.02 substitutions per site. Only bootstrap values $\geq 50 \%$ (based on 500 replicates) are labelled at branch points. There were a total of 164 amino acid residues in the final dataset 
are more abundant. Alternatively, the low number of bona fide mdh 2 sequences used to design primers may have resulted in primers that are specific to a narrow group of organisms. The identification of additional mdh2-possessing organisms might enable the design of primers with broader specificity.

\section{Diversity of $m x a F$ and $x o x F$ in soils}

The diversity of mxaF and $x o x F$ genes in the unplanted soil and rhizosphere samples was analysed by amplicon sequencing of PCR products generated using primers developed previously [28]. The $m x a F$ amplicons produced from DNA extracted from the unplanted and pea rhizosphere soil were dominated (>99\%) by three OTUs affiliated with Hyphomicrobium. This genus was present at $4.5-6 \%$ relative abundance in the 16S rRNA gene profile of the unplanted soil and pea rhizosphere bacterial communities, and, of the genera predicted to contain the $m x a F$ gene, Hyphomicrobium was the most abundant within these environments. The remainder of the $m x a F$ sequences $(<$ $1 \%)$ clustered with $m x a F$ sequences from members of the family Methylophilaceae (Additional File 3). The mxaF diversity detected in the Church Farm (CF) soil shows similarities to profiles originating from topsoils of other grassland sites reported in a previous study [18]. These authors identified OTUs affiliated with Hyphomicrobium and Methylophilaceae, which were also detected here in the Church Farm soil. However, we did not detect mxaF amplicons affiliated with Methylobacterium, which were detected at high abundance in these previously characterised grassland soils from the previous study [18].

PCR assays with primers specific for the xoxF5 clade revealed that the abundant xoxF5 OTUs retrieved from the unplanted and pea and wheat rhizosphere soils had high similarity to $x o x F 5$ from members of the Alphaproteobacteria and Betaproteobacteria (Fig. 2, Additional File 4), principally members of the genera Hyphomicrobium, Microvirga and Rhodopseudomonas. These genera were

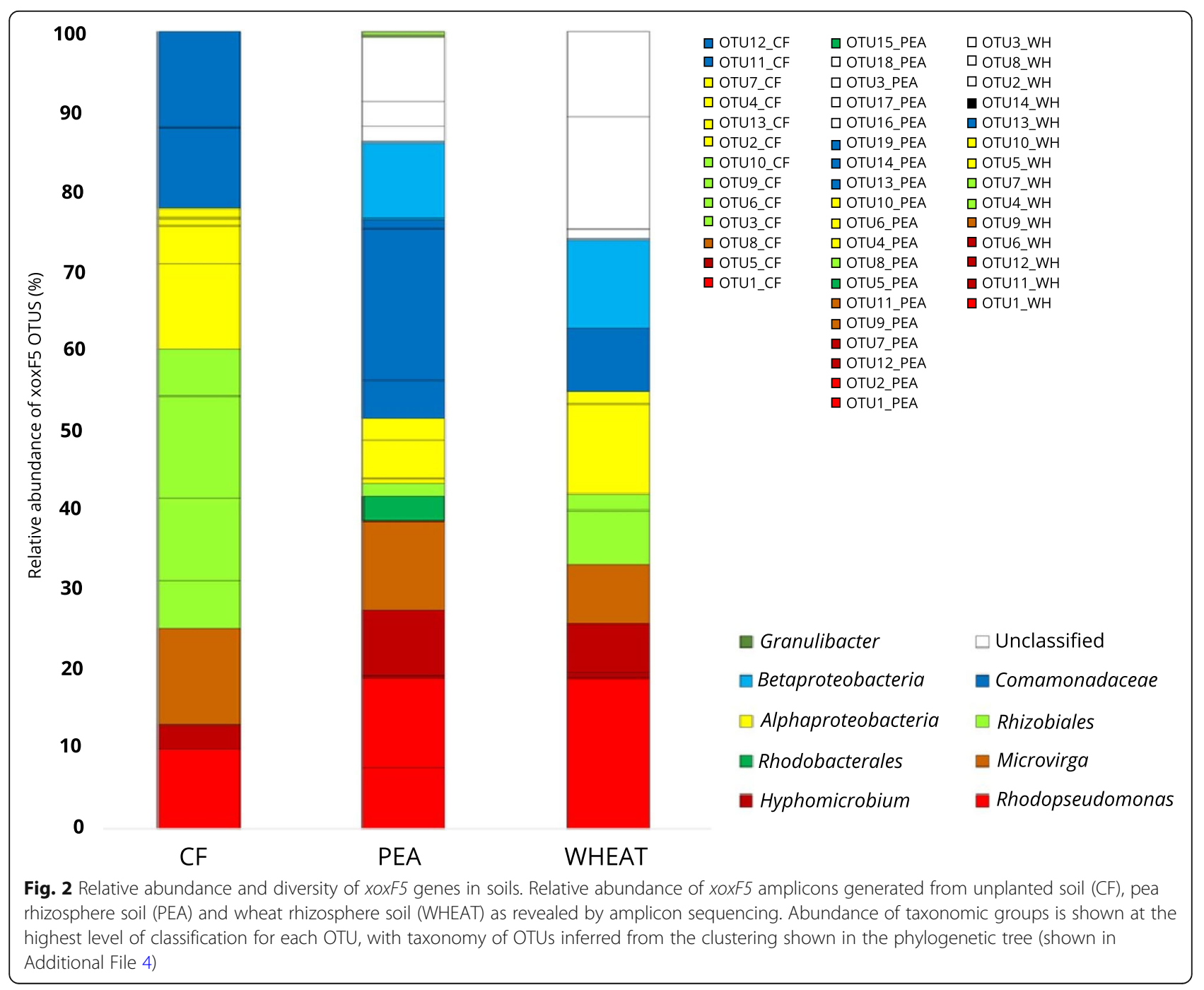


also detected in the 16S rRNA gene profiles and contain species capable of methanol oxidation [32-34]. The xoxF5 profiles of the rhizosphere environments were both enriched in OTUs with high similarity to sequences from Rhodopseudomonas, Hyphomicrobium and the Betaproteobacteria. The wheat rhizosphere also contained a greater number of divergent xoxF OTUs that could not be assigned a phylogeny. OTUs of xoxF5 representatives of members of the Comamonadaceae were detected in DNA from the pea rhizosphere at relatively high abundance $(\sim$ 25\%) (Fig. 2).

PCR primers specific to $x o x F 4$ consistently failed to yield $x o x F 4$ amplicons with DNA extracted from the unplanted soil, pea rhizosphere soil and wheat rhizosphere soil, indicating that this gene was either absent or below the limit of detection. Libraries of $x o x F 1, x o x F 2$ and xoxF3 amplicons were generated from DNA extracted from unplanted soil. Three of the xoxF1 OTUs (OTU1, 2 and 3) had high similarity to members of the Rhizobiales (Oharaeibacter, Methyloceanibacter and Hyphomicrobium). There was also an OTU (16\%, OTU 4) that did not have high similarity to any of the $x o x F 1$ reference sequences (Additional File 5). The xoxF3 clone library was dominated by OTU A (26/47 clones), most closely related to xoxF3 of Methylobacterium nodulans (Additional File 6). The additional diversity (OTUs D, F, G, H, I) (Additional File 6) was comprised of sequences clustering with xoxF3 genes of species of Methylosinus, a methanotroph, and Azospirillum (relative abundance $25.5 \%$ and $14.9 \%$ respectively). The most abundant xoxF2 OTU retrieved by xoxF2 amplicon sequencing was identical to a $x o x F 2$ clone obtained after screening a small clone library (see the "Methods" section). Because this $x o x F 2$ sequence was greater in length than $x o x F 2$ sequences obtained using Illumina technology, it was used in further phylogenetic analysis. The $x o x F 2$ sequence did not cluster with any of the reference sequences and showed highest similarity (84\%) to a putative $x o x F 2$ sequence found in metagenome-assembled genomes from studies investigating the microbial diversity of the Chinese and Japanese seas [35, 36] (Additional File 7). These genomes are assigned to the phylum Candidatus Entotheonella, which was not detected in the 16S rRNA gene sequence profile of the Church Farm soil.

\section{Quantification of $m x a F$ and xoxF5 genes in soils using qPCR}

The abundance of the $m x a F$ and $x o x F 5$ genes in the unplanted soil and pea and wheat rhizosphere was determined using qPCR. $x o x F 5$ was selected from the xoxF clades for quantification since $x o x F 5$ has been proven to be a bona fide methanol dehydrogenase-encoding gene in multiple species [37-39] and sequencing of xoxF5 gene amplicons from the three different habitats identified shifts in diversity that were potentially correlated with shifts in abundance. Furthermore, the primers for $x o x F 3$ and $x o x F 1$ are unsuitable for $\mathrm{qPCR}$ analysis and their redesign was outside of the scope of this work. xoxF4 was not selected for quantification as it was not detected in the unplanted soil DNA and the primers for $x o x F 4$ have cross-specificity for $x o x F 5$ genes in the absence of xoxF4 [28].

Normalised to $16 \mathrm{~S}$ rRNA gene copy number, the qPCR assays showed that within the three soil environments tested, xoxF5 genes were 36-42 times more abundant than $m x a F$ genes (Additional File 8). However, the overall abundance of methanol dehydrogenase genes did not differ significantly between the three soil environments (two-way ANOVA, $p=0.567$ ). Despite the prevalence of multiple $x o x F 5$ copies in genomes, these data support the hypothesis that Xox enzymes are more abundant and have a wider distribution than Mxa-type MDHs in this type of environment [24]. This confirms the need to also investigate the diversity and distribution of $x o x F$ genes when characterising the diversity of methylotrophic bacteria in environmental studies.

\section{The impact of plants on soil methylotrophs as assessed by DNA-SIP}

Using the same three soil treatments described above (unplanted, pea and wheat rhizosphere), the influence of plant growth on soil methylotrophs was examined to determine the differential response of these plant root-associated soil communities to addition of methanol. DNA-SIP enrichments were set up with each soil type using either ${ }^{13} \mathrm{C}$-labelled or ${ }^{12} \mathrm{C}$-unlabelled methanol. Following incorporation of ${ }^{13} \mathrm{C}$-label, the active methanol-assimilating taxa present in the rhizosphere of these two plant types were compared to the unplanted control soil, by amplicon sequencing of 16S rRNA genes of the ${ }^{13} \mathrm{C}$-labelled DNA retrieved from incubations with ${ }^{13} \mathrm{C}$-methanol after 6 and 17 days of incubation (T1 and $\mathrm{T} 2$ respectively).

Analysis of the 16S rRNA genes, after DNA-SIP incubations of the methanol-enriched unplanted soil at T1, identified Methylophilus and Methylotenera as ${ }^{13} \mathrm{C}$ labelled, with Methylophilus representing 90\% of the $16 \mathrm{~S}$ rRNA genes retrieved from the heavy DNA. The ${ }^{13} \mathrm{C}$-labelled communities of the T1 heavy fractions of the methanol-enriched pea and wheat rhizosphere soils were more diverse than that of the unplanted soil (Additional File 9). The ${ }^{13} \mathrm{C}$-labelled genera in the pea rhizosphere at T1 were identified as Methylophilus, Methylobacterium, Methylobacillus, Methylotenera and Opitutus (Fig. 3, Additional File 10), and the same methylotrophic genera were labelled in the wheat rhizosphere, but with a higher relative abundance of Methylophilus.

In the unplanted soil incubations, the relative abundance of 16S rRNA genes of Methylobacillus, Methylocystis and 


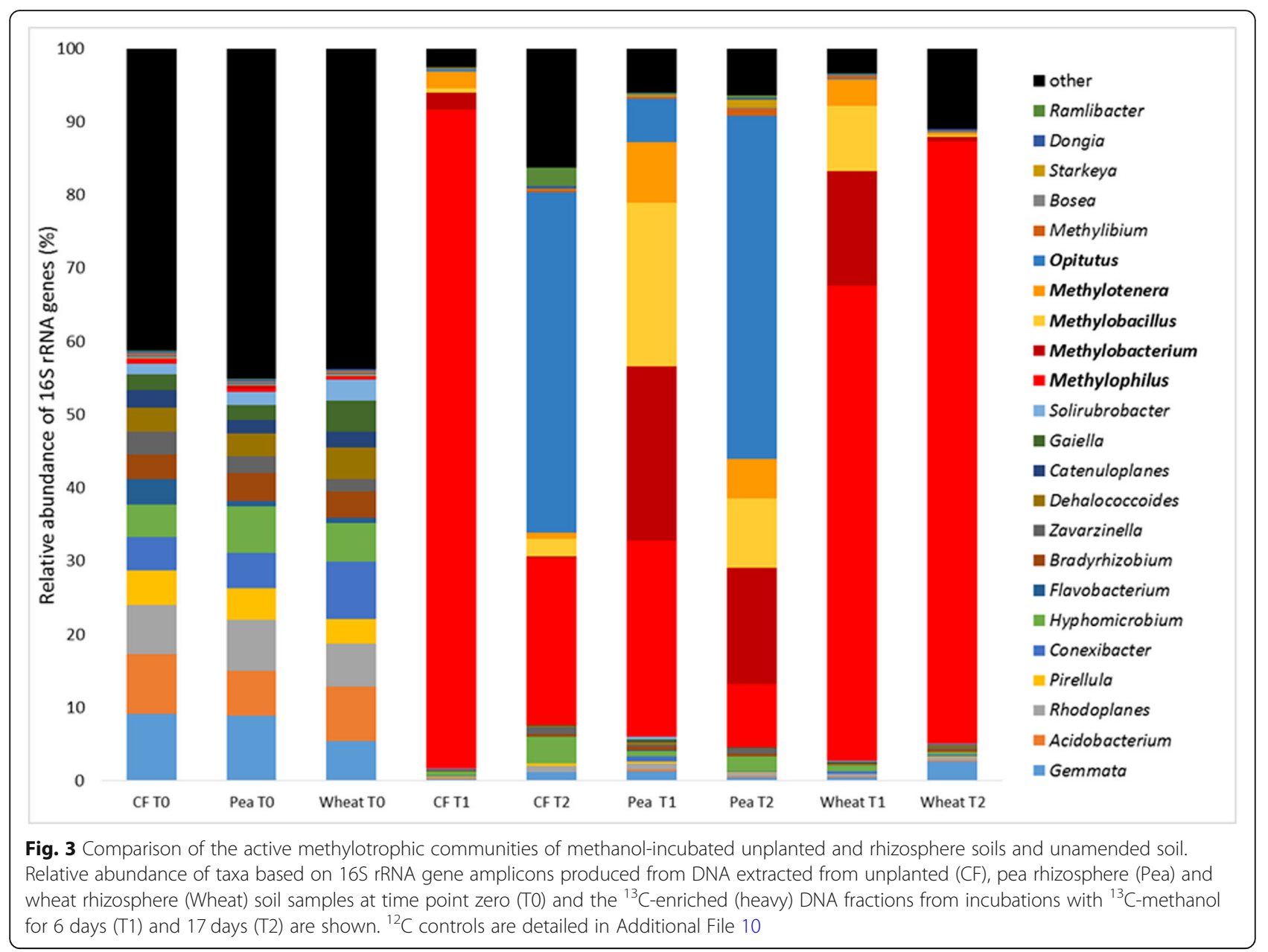

Methylotenera increased between $\mathrm{T} 1$ and $\mathrm{T} 2$, but in addition to these known methylotrophs, Opitutus was detected as enriched in the heavy fraction, present at $42 \%$ relative abundance $16 \mathrm{~S}$ rRNA genes retrieved from the heavy fraction. In the pea rhizosphere, of the genera ${ }^{13} \mathrm{C}$ labelled at T1, only Opitutus increased in relative abundance at T2, increasing from 5 to $24 \%$. However, 13 additional genera were labelled, notably Starkeya (1.1\%). In the wheat rhizosphere, fewer genera were labelled at T2 compared with T1 and comprised of only Methylophilus and Methylotenera. The relative abundance of Methylotenera decreased tenfold to $0.34 \%$, whereas the relative abundance of Methylophilus increased from 64 to $82 \%$.

Additional groups of bacteria ${ }^{13} \mathrm{C}$ labelled in the rhizosphere soil DNA-SIP experiment, albeit in low abundance, were Stigmatella $(0.32 \%$ in the wheat rhizosphere and $1.19 \%$ in the pea rhizosphere) and members of the phylum Lentisphaerae $(0.11 \%$ in the wheat rhizosphere). Based on the lack of $\mathrm{MDH}$ genes in published genome sequences and previous phenotypic characterisation of representatives of Stigmatella and Lentisphaerae [40, 41], it is possible that they were ${ }^{13} \mathrm{C}$ labelled by cross feeding. Enrichment of Opitutus was also unexpected, as members of this genus are not known to be methanoloxidising bacteria [42].

\section{Metagenomes reconstructed from DNA-SIP experiments}

In addition to sequencing $16 \mathrm{~S}$ rRNA gene amplicons, the active methanol-assimilating taxa in the rhizosphere and unplanted soils were further characterised by shotgun sequencing the ${ }^{13} \mathrm{C}$-labelled DNA retrieved from the DNA-SIP incubations enriched with ${ }^{13} \mathrm{C}$-methanol at T2, resulting in a metagenome for each of the three environments. Metaphlan2 (2.0) [43] was used to analyse the taxonomic composition of the three metagenomes using the presence of taxonomically informative marker genes (the database of these marker genes can be accessed at http://huttenhower.sph.harvard.edu/metaphlan). The metagenomes were dominated by bacteria, specifically Proteobacteria. Gene sequences identified as from Eukarya, Archaea or viruses were present at below $0.1 \%$ relative abundance (Fig. 4 ).

Consistent with the $16 \mathrm{~S}$ rRNA gene profiling described above, this metagenomics approach identified members of 
the Methylophilaceae as highly abundant in all three environments. Furthermore, a key genus delineating the methanol-enriched plant environments from the methanol-enriched unplanted soil was Methylobacterium. This was present at $14.7 \%$ relative abundance in the pea rhizosphere and $1.5 \%$ in the wheat rhizosphere. It was not detected in the unplanted controls. Analysis of the metagenomes confirmed the differences observed between the planted and unplanted soils using 16S rRNA gene amplicon sequencing. The metagenomes revealed a higher diversity than the $16 \mathrm{~S}$ rRNA gene amplicon approach
(Additional File 9). The additional genera detected in the metagenomes that were shared between the environments include Mesorhizobium, Methylibium, Variovorax and Rhodospirillum. The metagenomes also showed more differences in community composition between the two planted soils, with Comamonas, Sphingobium, Rhizobium, Leifsonia, Mesorhizobium and Methylophilus all being present at greater abundance in DNA from the methanolenriched wheat community whilst Variovorax, Bradyrhizobium, Afipia, Asticcacaulis and Rhodospirillum were present at greater abundance in DNA from the methanol-

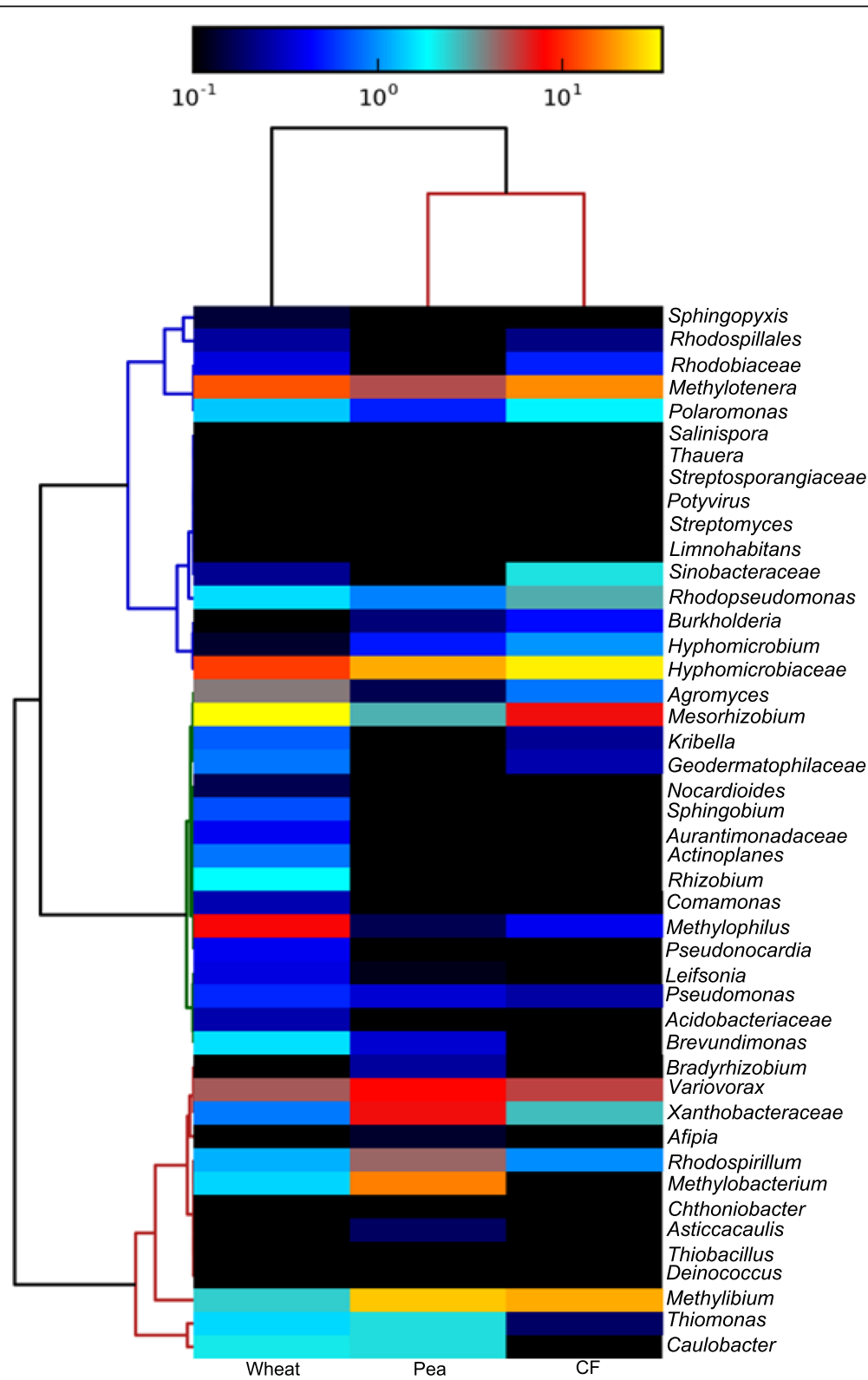

Fig. 4 Metagenome-derived community profiles produced from the ${ }^{13} \mathrm{C}$-enriched (heavy) DNA fractions of ${ }^{13} \mathrm{C}$ methanol-enriched soils. Sequences were revealed by shotgun sequencing of ${ }^{13} \mathrm{C}$-enriched DNA extracted from wheat rhizosphere soil (Wheat), pea plant rhizosphere soil (Pea) and unplanted soil (CF) incubated with ${ }^{13} \mathrm{C}$-labelled methanol for 17 days. Relative abundance of taxa is indicated by the colorimetric key assigned with a log scale, with yellow indicating abundance $>10^{1}$ cells of a taxon and black representing an absent taxon 
enriched pea rhizosphere community. In comparison with the unplanted soil, these data show that the rhizosphere soils contain multiple taxa poised to take advantage of additions of methanol. This lends weight to the hypothesis that plants support a higher diversity of bacteria, in particular methylotrophs, than are present in unplanted soil.

The metagenomes were screened for genes of interest using the blast function of BioEdit. This identified the presence of genes encoding for methanol dehydrogenases ( $x o x F$ and $m x a F$ ), enzymes involved in methylated amine utilisation (tmmD, dmmD, mauA and the $\mathrm{N}$ methylglutamate pathway) and formaldehyde and formate oxidation in all three metagenomes. The screening also identified all the genes of the ribulose monophosphate and serine cycles. Genes encoding the complete pathways for assimilatory sulfate reduction, denitrification and nitrogen fixation were also detected in the three metagenomes, providing an insight into the energy and nitrogen yielding pathways active in the three soil habitats. The screening for genes of interest did not reveal a difference in the presence of these metabolic pathways between the metagenomes. To investigate differences in the abundance and diversity of methanol dehydrogenase-encoding genes in the three methanol-enriched soil habitats, the assembled and unassembled reads of the metagenomes were screened with representative sequences of each clade of methanol dehydrogenase-encoding gene (xoxF1, xoxF2, $x o x F 3, x o x F 4, x o x F 5, m x a F$ and $m d h 2)$. The abundance of methanol dehydrogenase genes differed between the three metagenomes (Additional Files 11, 12, 13, 14, 15, 16). $m x a F$ and $x o x F 4$ were present at higher abundance in the two plant habitats relative to the unplanted soil, whereas xoxF5 and xoxF3 were more abundant in the pea rhizosphere relative to the unplanted soil and wheat rhizosphere. $m d h 2$ sequences were only detected in the methanol-enriched pea rhizosphere and unplanted soils, and these sequences showed high $(>82 \%)$ sequence identity to those of Methylibium and Methyloversatilis (Additional File 16). The diversity of the xoxF3 sequences detected in the metagenomes was greatest in the methanol-enriched pea rhizosphere soils (Additional File 16), which included sequences with high sequence identity to those possessed by members of the genera Methylobacterium and Mesorhizobium, in addition to the Comamonadaceae sequences detected in the other two enriched soil habitats (Additional File 16). $x o x F 2$ and $x o x F$ outgroup sequences (the Acidiphilum and Methylosinus trichosporium sequences that do not cluster with any established clade [23]) were not detected in the three metagenomes.

$x o x F 5$ was the most abundant methanol dehydrogenaseencoding gene in the pea rhizosphere and unplanted soil but was only the second most abundant in the wheat rhizosphere, where the most abundant was xoxF4. Compared to the number of copies of mxaF and xoxF5 determined by qPCR for soils that were not enriched with methanol, these data show that following enrichment with methanol, xoxF5 was present at greater abundance than $m x a F$, but both genes were present at the same order of magnitude in all three soil habitats. The $x o x F 1$, xoxF5 and $m x a F$ sequences detected in the metagenomes arising from the methanol-enriched pea and wheat rhizospheres and unplanted soils showed similar patterns of diversity to the sequenced amplicons produced from the unenriched soil. The $x o x F 1$ sequence profiles revealed low levels of diversity, with the detected $x o x F 1$ sequences showing high sequence identity to those identified in genomes of strains of Hyphomicrobium and Methyloceanibacter (Additional File 12). The diversity of $m x a F$ sequences was also low, with the $m x a F$ sequences detected having high sequence identity to mxaF genes from Hyphomicrobium, Methylobacterium and Methylophilus in all three metagenomes (Additional File 15). The xoxF5 sequences in the three metagenomes showed high sequence identity to sequences identified in members of the Alphaproteobacteria (Rhizobium, Methylobacterium and Hyphomicrobium) and Betaproteobacteria (Methylibium and Comamonadaceae), with similar sequence diversity detected between the three soil habitats (Additional File 14). There was also similarity in the diversity of the xoxF4 sequences detected in the three methanol-enriched habitats, with high sequence identity to members of four genera within the Methylophilaceae (Methylomonas, Methylophilus, Methylobacillus and Methylovorus) (Additional File 13), but this might be an artefact of the low diversity of this clade of methanol dehydrogenase-encoding gene.

To further investigate the diversity of the methanolenriched environments, assembled sequence data from the three metagenomes were binned into metagenome assembled genomes (MAGs). The binning produced 10 MAGs of sufficient quality (completeness score $>70 \%$ and contamination $<10 \%$ ), meeting currently accepted criteria for medium- to high-quality MAGs [44]) (Additional File 17). These MAGs were also screened for genes of interest (Additional File 18). One genome (vs26) was identified as a Rubrivivax. This MAG contained a xoxF5 methanol dehydrogenase-encoding gene, genes encoding a complete tetrahydromethanopterin formaldehyde oxidation pathway [45], thiosulfate oxidation (soxABXYZ) and assimilatory sulfate reduction ( cysCDHIJN), as well as an incomplete serine cycle. The genome binning also produced a MAG classified as a Methylobacterium (ss20), an abundant genus in the methanol-enriched pea and wheat rhizosphere soils. This MAG contained mxaF and xoxF5 methanol dehydrogenase genes, and genes encoding the complete $\mathrm{N}$-methyl glutamate pathway for methylamine utilisation [46], an incomplete serine cycle and one of each of the four forms of formate dehydrogenase [47-49]. However, we 
cannot rule out the possibility that the incomplete serine cycle of these MAGs may be an artefact resulting from imperfect sequence assembly or binning (predicted MAG completeness $97 \%$ and $72 \%$ respectively).

Of the remaining MAGs, three were members of the order Methylophilales, highly enriched in all of the soil environments supplemented with methanol. The methanol dehydrogenase gene of the MAG-designated Methylotenera ss03 was of note, as the xoxF3 did not cluster with those of other Methylophilaceae (i.e. Methylobacillus flagellatus), but instead with Variovorax paradoxus strain S110 and sequences from the Alphaproteobacteria (Additional File 19), suggesting that the diversity of this clade of methanol dehydrogenase within the Methylophilaceae is greater than previously detected. The MAGdesignated Methylophilales ss 01 and ss 29 were of interest as they showed high levels of similarity to the strains Methylobacillus sp. strain MM3 (97\% average nucleotide identity (ANI)) and Methylovorus sp. strain MM2 (99\% ANI) respectively, both of which were previously isolated from the same environment [50]. Despite the fact that enrichment and isolation techniques may not capture all representatives of the bona fide natural community, this suggests that both strains may have been active members of the methanol-oxidising community of this soil. In addition to methanol dehydrogenase genes, these MAGs contain formate dehydrogenases and partially complete ribulose monophosphate cycles.

Further analysis of the MAGs Archaea vs43, Bdellovibrio vs70, Deltaproteobacteria ss68 and Verrucomicrobia vs53 and ss71 showed that none of them contained a methanol dehydrogenase-encoding gene or genes encoding formaldehyde utilisation pathways. However, the MAGs Verrucomicrobia ss101 and Deltaproteobacteria ss68 both contain copies of a formate dehydrogenase (fdh4)-encoding gene and the genome ss68 possessed genes encoding dimethylamine and trimethylamine dehydrogenases, implying that these strains of bacteria may be able to utilise some $\mathrm{C} 1$ compounds as carbon and/or nitrogen sources. The enrichment of these taxa with ${ }^{13} \mathrm{C}$ could therefore be explained by the utilisation of exuded $\mathrm{C} 1$ compounds (i.e. formate), utilisation of other exuded organic compounds, the fixation of ${ }^{13} \mathrm{C}$-labelled $\mathrm{CO}_{2}$ produced by the methanol oxidising methylotrophs (in the case of vs43, which contains the gene for ribulose-1,5-bisphosphatecarboxylase/oxygenase) or, in the case of Bdellovibrio (vs70), predation on the methanol oxidising methylotrophs [51].

\section{Phylogenetic analysis of the exudate-utilising community of the pea rhizosphere}

In a third series of experiments, DNA-SIP was also utilised to investigate whether methylotrophic bacteria were utilising carbon exuded from the roots of plants.
Pea plants were incubated in a ${ }^{13} \mathrm{CO}_{2}$ or ${ }^{12} \mathrm{CO}_{2}$ (control) atmosphere for 12 days to allow sufficient ${ }^{13} \mathrm{C}$ label to be incorporated into plant biomass and then for ${ }^{13} \mathrm{C}$-labelled plant exudate released from roots to be assimilated by microbes in the rhizosphere. Two $\mathrm{CO}_{2}$ concentrations were used, 350 and 1000 ppmv, reflecting environmental and elevated levels. Three hundred fifty parts per million volume was selected as the concentration of $\mathrm{CO}_{2}$ to supply to the environmental test group, as $\mathrm{CO}_{2}$ was also released by the soil, and this ensured the concentration did not exceed environmental levels (420 ppm).

The bacteria in the pea rhizosphere that were active utilisers of plant exudates were identified by sequencing of 16S rRNA gene amplicons generated from heavy and light DNA fractions retrieved from rhizosphere and unplanted (control) soils. Analysis of $16 \mathrm{~S}$ rRNA gene sequences retrieved from heavy fractions of DNA obtained in DNA-SIP experiments with pea plants incubated with ${ }^{13} \mathrm{CO}_{2}$ indicated that labelling of bacteria of the genera Novosphingobium (4.8\% relative abundance after enrichment with 350 ppmv ${ }^{13} \mathrm{CO}_{2}$ and $17.7 \%$ relative abundance after enrichment with 1000 ppmv), Kaistobacter (1.9\% at $350 \mathrm{ppmv}$ and $4.4 \%$ at $1000 \mathrm{ppmv})$, Sphingomonas $(2.9 \%$ at $350 \mathrm{ppmv}$ and $6.2 \%$ at $1000 \mathrm{ppmv})$, Paracoccus ( $0.2 \%$ at 350 ppmv), Variovorax (1.4\% at 350 ppmv), Flavobacterium (1.8\% at $350 \mathrm{ppmv})$ and Ramlibacter (0.\% at $350 \mathrm{ppmv})$, Methylocapsa (0.5\% at 1000 ppmv) and Leptothrix (0.4\% at $1000 \mathrm{ppmv})$ occurred (Fig. 5). With the exception of Novosphingobium and Kaistobacter, these genera contain species that are either methylotrophs or whose genomes contain $x o x F$ genes $[11,52-54]$. The addition of an elevated concentration of carbon dioxide to growing grasses and sedges has previously been shown to impact on the rhizosphere community [55]. The observation that growing pea plants with different levels of $\mathrm{CO}_{2}$ might favour the growth on root exudates of different groups of methylotrophs is interesting and warrants further investigation in the future.

Variovorax, Ramlibacter and Leptothrix genera within the Comamonadaceae were ${ }^{13} \mathrm{C}$ labelled in the rhizospheres of pea plants incubated with ambient and elevated ${ }^{13} \mathrm{CO}_{2}$. Strains from these genera have previously been found in rhizosphere environments [56-59]. The family Comamonadaceae contains bacteria that are metabolically versatile and can use a broad range of carbon substrates, enhance the cycling of sulfur in soil and suppress fungal pathogens [57, 60]. Genera within this family include Variovorax and Delftia, which contain species known to grow on methanol [58, 61]. An examination of all available genomes of members of the Comamonadaceae revealed that representatives of 28 out of 34 genera contain $x o x F$ genes. With the 


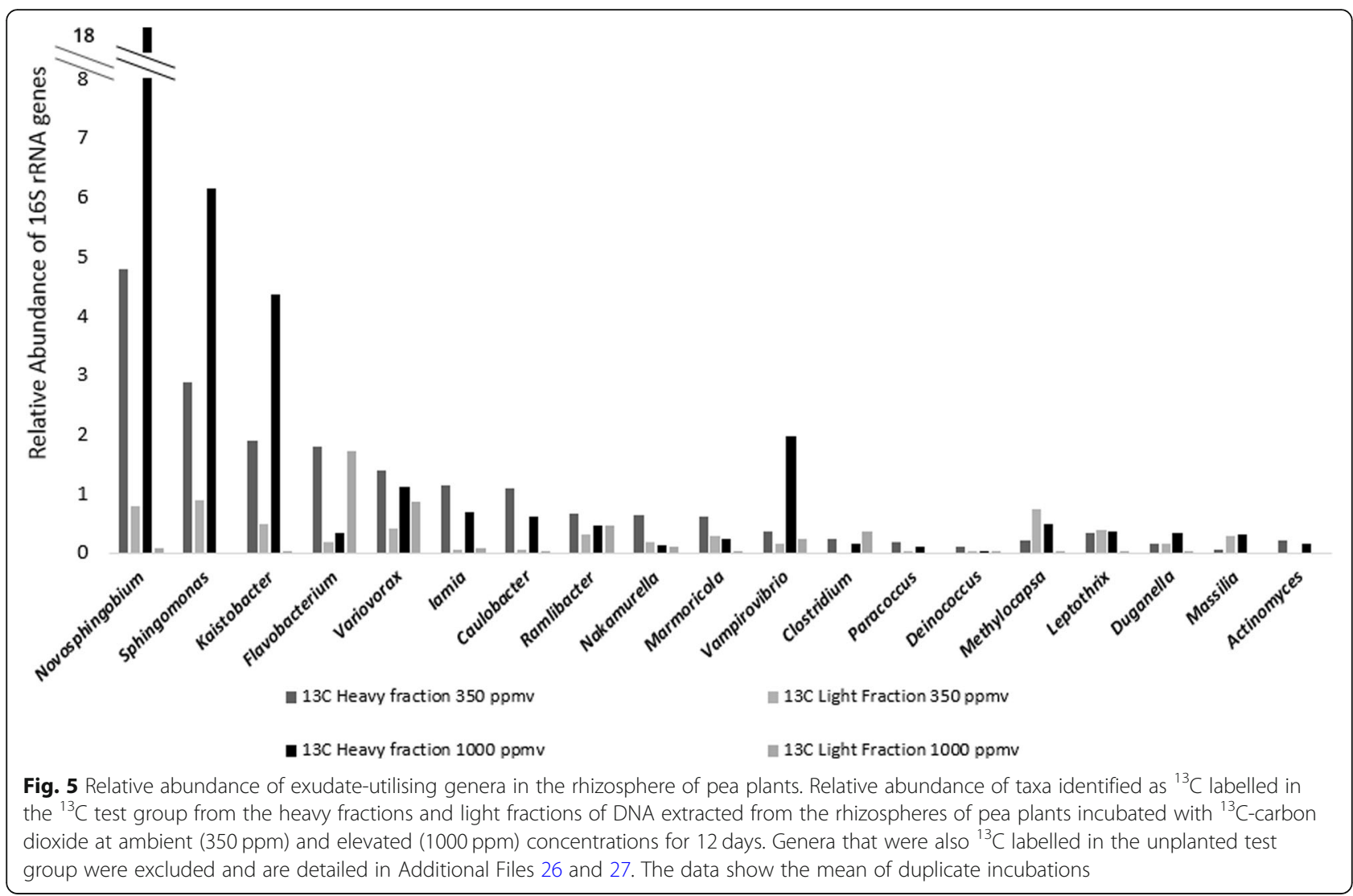

recent discovery of the role of lanthanides in methylotrophy, there is a clear need to retest representatives of the Comamonadaceae for their ability to grow on methanol in medium supplemented with these rare earth elements.

Labelling of members of the Sphingomonadaceae and Actinobacteria in our DNA-SIP experiments is consistent with previous reports with other plant species [6264], and the utilisation of exudates by members of the Sphingomonadaceae has been observed in stable isotope probing experiments and the rhizosphere of rice plants [65]. Actinobacteria are proposed to play a role as plant growth promoting bacteria through the production of antimicrobial or antifungal agents, plant hormones and siderophores [87 and references therein]. In ${ }^{13} \mathrm{CO}_{2}$ rhizosphere SIP studies with oil seed rape, wheat, maize and Medicago truncatula, Actinobacteria were also observed to use root exudates $[2,64]$. The ${ }^{13} \mathrm{C}$ labelling of members of the Actinobacteria and Sphingomonadaceae in stable isotope probing studies implies they incorporated carbon exuded by the plant, suggesting that they were enriched in the rhizospheres of different plant species because of direct utilisation of plant exudates rather than cross feeding.

Comparing the 16S rRNA gene and methanol dehydrogenase gene amplicons produced from DNA extracted from the unenriched unplanted soil and rhizosphere soils to the taxonomic profiling of the labelled communities from soils that were enriched with either ${ }^{13} \mathrm{C}$-methanol or ${ }^{13} \mathrm{CO}_{2}$ identified that a small portion of diversity was common between these different test groups (e.g. Variovorax, Additional Files 20, 21, 22). However, beta diversity analysis (Additional File 23) clearly shows that the communities in the methanolenriched samples cluster separately from the $\mathrm{CO}_{2}$ enriched samples. This difference is largely due to the high levels of enrichment of members of the Methylophilaceae in the soils amended with methanol and their absence in the exudate utilising population of the pea rhizosphere.

\section{Conclusions}

Growing plants are a major source of methanol, and the microbial community phyllosphere of multiple plant species has been shown to include methylotrophs that are highly abundant [66-68]. However, there have been few studies attempting to characterise the impact of plant growth on the diversity and activity of methylotrophs in the rhizosphere and whether they are using carbon directly from the plant. In this study, methylotrophs were shown to be abundant in the unplanted soil, pea rhizosphere soil and wheat rhizosphere soil, and 
their diversity was influenced by pea and wheat plants. The use of $x o x F$ and $m x a F$ as functional gene markers revealed a greater diversity of methylotrophs in the rhizosphere than previously observed by $16 \mathrm{~S}$ rRNA gene sequencing, with $x o x F$ shown to be the more relevant indicator of methylotrophy in these soil environments and also an order of magnitude more abundant than mxaF. However, $m d h 2$ currently is of limited utility in characterising the diversity of methylotrophs in soils.

Metagenome sequencing of ${ }^{13} \mathrm{C}$-labelled DNA extracted from pea and wheat rhizosphere soils and unplanted soils enriched with methanol confirmed that the growth of pea and wheat plants influenced methylotrophy. Interestingly, both plant associated environments showed the same shift in the microbial community profile, revealing a greater diversity of members of the Methylophilaceae and Methylobacterium, a cosmopolitan genus possessing plant growth-promoting traits and commonly associated with plants $[30,69,70] .{ }^{13} \mathrm{CO}_{2}$ labelling of growing pea plants also confirmed that methylotrophs present in the pea rhizosphere were actively utilising carbon exudate from the plant. Comparing the methylotrophic genera detected in the pea rhizosphere, by sequencing of methanol dehydrogenase genes from the unplanted soil, from the exudate-utilising population from the ${ }^{13} \mathrm{CO}_{2}$ SIP experiment and from soils enriched with ${ }^{13} \mathrm{C}$ methanol, revealed that, using these approaches, only a minority of the diversity was shared. The differential enrichment of methylotrophs between the two SIP experiments indicates that there could be selection for some genera of methylotrophs in response to the higher concentrations of methanol (e.g. Methylophilaceae) whilst others can utilise methanol at a wider range of concentrations (e.g. Comamonadaceae).

Plants can also influence the availability of micronutrients, soil structure, $\mathrm{pH}$ and redox potential [62], and these factors could play a role in the recruitment of methylotrophs to the rhizosphere. Furthermore, the specific growth stages of the plants used in this series of experiments and their stress state might affect the amount and nature of exudate released from the roots $[19,71]$. Both factors might impact on the activity of methylotrophs in the soil. Additional studies are therefore needed to define the exact relationship between methylotrophs and the rhizosphere.

\section{Methods}

\section{Chemicals and reagents}

Analytical grade reagents used were from Sigma-Aldrich (MO, USA), Melford Laboratories (Ipswich, UK) or Fisher Scientific (Loughborough, UK). Molecular biology grade reagents were from Thermo Fisher (MA, USA), Promega UK (Southampton, UK), Qiagen (Germany) and Roche (Switzerland). Gases were supplied by BOC
(UK). ${ }^{13} \mathrm{CO}_{2}$ and ${ }^{13} \mathrm{C}$-labelled methanol were supplied by Cambridge Isotope Laboratories (MA, USA). All ultracentrifuge work involved using tubes, rotors and ultracentrifuges from Beckman Coulter (CA, USA).

The experimental workflow for the research described in this study is detailed in Additional File 24.

\section{Collection, processing and storage of soil}

Soil was collected in April 2015 from a naturally grassed and unfertilised part of John Innes Centre Church Farm (Norfolk, UK) (52.6276 N, $1.1786 \mathrm{E})$. The top $10 \mathrm{~cm}$ was removed from a $1 \mathrm{~m}^{2}$ section and then soil to $20 \mathrm{~cm}$ depth was removed, air dried and sieved through $10 \mathrm{~mm}$ and $5 \mathrm{~mm}$ sieves which removed stones, roots and other detritus. This soil (designated "bulk soil") was then used in all experiments.

\section{Extraction of nucleic acids from soil}

DNA was extracted from soil samples using a cetyltrimethyl ammonium bromide (CTAB)-based method [72] and quantified using Qubit fluorometric quantitation (Thermo Fisher).

\section{Germination and growth of plants}

Paragon wheat seeds (Triticum aestivum var. Paragon) were sterilised by washing the seeds in $5 \%(\mathrm{v} / \mathrm{v})$ sodium hypochlorite solution for $1 \mathrm{~min}$. Pea seeds (Pisum sativum var. Avolar) were sterilised by washing the seeds in 95\% (v/v) ethanol for $1 \mathrm{~min}$, washing with sterile $\mathrm{H}_{2} \mathrm{O}$ and soaking in $2 \%(\mathrm{w} / \mathrm{v})$ sodium hypochlorite for $5 \mathrm{~min}$. Pea and wheat seeds were then washed in sterile $\mathrm{H}_{2} \mathrm{O}$ and placed in a petri dish on filter paper disks moistened with sterile $\mathrm{H}_{2} \mathrm{O}$ [13]. The seeds were left in the dark for 3 days to germinate and manually inspected for fungal contamination before planting in $10 \mathrm{~cm} \times 10 \mathrm{~cm}$ pots in bulk soil and growing at $22^{\circ} \mathrm{C}$ under long day regimes $(16: 8 \mathrm{~h})$ in plant growth rooms. Pots with unplanted soil were incubated alongside the growing plants as unplanted controls. Plants were harvested after 4 weeks of growth. Excess soil was removed by shaking the roots three times. Soil that remained attached to the roots after shaking was defined as rhizosphere soil. Rhizosphere soil was removed by transferring the roots to Falcon tubes, submerging in phosphate buffered saline (PBS) and vortexing for $30 \mathrm{~s}$. Tubes were centrifuged at $3200 \times g$ for $15 \mathrm{~min}$ to pellet soil. Root material was removed and the supernatant discarded. DNA was extracted from three separate $0.5 \mathrm{~g}$ aliquots of soil and subsequently pooled to produce a composite sample.

\section{DNA-SIP with ${ }^{13} \mathrm{C}$ methanol}

Two grams of aliquots of rhizosphere soil, collected as described above, and unplanted soil were dispensed into $120-\mathrm{ml}$ serum vials. Forty millilitres of sterile $\mathrm{H}_{2} \mathrm{O}$ was 
added to reduce the heterogeneity of the soil sample within the serum vials and to facilitate substrate distribution. Vials were then supplemented with ${ }^{13} \mathrm{C}$ methanol or ${ }^{12} \mathrm{C}$ methanol to a concentration of $250 \mu \mathrm{M}$ and sealed. Each test group was performed in triplicate. The serum vials were incubated at $30^{\circ} \mathrm{C}$ without light in a shaking incubator $(120 \mathrm{rpm})$. The concentration of methanol in the headspace of the serum vials was measured using gas chromatography (GC) on an Agilent 7820A instrument, using a flame ionisation detector, a Porapak Q column $\left(6 \mathrm{ft} \times 1 / 8^{\prime \prime} \times 2.1 \mathrm{~mm}\right)$ and helium carrier gas (injector temperature, $300^{\circ} \mathrm{C}$; detector temperature, $300^{\circ} \mathrm{C}$; oven temperature, $115^{\circ} \mathrm{C}$ ). After depletion of methanol, samples were resupplied with methanol to the same concentration. Serum vials were opened every second day and flushed with air to prevent the development of anaerobic conditions and to avoid the build-up of ${ }^{13} \mathrm{CO}_{2}$ within vials. After 6 days, when methanol oxidation stopped, samples were taken from enrichments for DNA extraction (time point 1). Dilute nitrate mineral salts medium [73] $(1 \mathrm{ml})$ was supplied to the serum vials on day 7 to establish whether the enrichments were nutrient limited and the incubations were continued. Methanol consumption resumed. After 17 days, a total of $200 \mu \mathrm{mol}$ of ${ }^{13} \mathrm{C}$ had been consumed in incubations and soil was collected for DNA extraction (time point 2). DNA was extracted from all soil samples, and caesium chloride density gradient centrifugation was used to separate the ${ }^{13} \mathrm{C}$ - and ${ }^{12} \mathrm{C}$-labelled DNA from 1$3 \mu \mathrm{g}$ of DNA from each test group according to established protocols [74]. During fractionation of $\mathrm{CsCl}$ gradients, twelve samples were collected and the density of $\mathrm{CsCl}$ in each fraction estimated by measuring the refractive index (Reichert AR200). DNA was then recovered by precipitation [74].

DNA stable isotope probing with ${ }^{13} \mathrm{CO}_{2}$

Pea plants were grown in $10 \mathrm{~cm} \times 10 \mathrm{~cm}$ pots in bulk soil under long day growth conditions (16h:8h) for 16 days. After 16 days, eight pea plants and eight unplanted soil controls were transferred to acrylic tubes (approx. $3.8 \mathrm{~L}$ volume, $400 \mathrm{~mm}$ height $\times 110 \mathrm{~mm}$ internal diameter). All plants and unplanted soil controls were transferred to medium day light conditions (12 h:12 h). The acrylic tubes were flushed with carbon dioxide depleted air, sealed with plastic lids and injected with either ${ }^{13} \mathrm{CO}_{2}$ or ${ }^{12} \mathrm{CO}_{2}$ to a final concentration of either 350 ppmv or 1000 ppmv, with each experimental condition in duplicate. Carbon dioxide was measured by GC on an Agilent 7890A instrument equipped with a nickel catalyst, using a flame ionisation detector, an HP plot/Q (30 $\mathrm{m} \times 0.530 \mathrm{~mm}, 40 \mu \mathrm{M}$ film) and helium carrier gas (injector temperature, $250{ }^{\circ} \mathrm{C}$; detector temperature, $300^{\circ} \mathrm{C}$; oven temperature, $50^{\circ} \mathrm{C}$ ). Carbon dioxide was replenished to the target concentration every 20 min during the light period. After 12 days, plants were harvested and DNA extracted from the rhizosphere soil. DNA $(4 \mu \mathrm{g})$ for each sample was processed via ultracentrifugation and fractionation as described above.

\section{Criteria for confirming ${ }^{13} \mathrm{C}$ labelling of DNA from target microbes}

Specific criteria were applied when analysing DNA sequence data from both SIP experiments to establish which taxa of bacteria were labelled. In order to be included in the analysis, the relative abundance of a specific taxon in the ${ }^{13} \mathrm{C}$-heavy DNA fraction had to be greater than $0.1 \%$. The criteria that needed to be fulfilled for a particular taxon to be considered ${ }^{13} \mathrm{C}$ labelled were as follows: (1) the relative abundance in the ${ }^{13} \mathrm{C}$-heavy fraction should be higher than in the ${ }^{12} \mathrm{C}$-heavy fraction $\left({ }^{13} \mathrm{C}_{\mathrm{H}}>{ }^{12} \mathrm{C}_{\mathrm{H}}\right)$ and (2) the taxon should be enriched in the heavy fraction of ${ }^{13} \mathrm{C}$ incubations (i.e. the relative abundance in the heavy fraction should be greater, by a specific factor, than in the light fraction $\left({ }^{13} \mathrm{C}_{\mathrm{H}}>k \times\right.$ ${ }^{13} \mathrm{C}_{\mathrm{L}}$ ), but this should not be the case for ${ }^{12} \mathrm{C}$ incubations $\left({ }^{12} \mathrm{C}_{\mathrm{H}} \leq{ }^{12} \mathrm{C}_{\mathrm{L}}\right)$. The factor $k$ was chosen as $k=10$ for the methanol SIP experiment, due to the substrate based stable isotope approach used and the probability of cross feeding, but $k=2$ in the ${ }^{13} \mathrm{CO}_{2}$-labelling SIP experiment, due to the more transient nature of the ${ }^{13} \mathrm{C}$ labelling and the lower input of ${ }^{13} \mathrm{C}$. Any enrichment of autotrophic bacteria could be accounted for and observed by incubating unplanted soil controls in a ${ }^{13} \mathrm{CO}_{2}$ atmosphere. Any taxon identified as ${ }^{13} \mathrm{C}$ labelled in the unplanted test group was excluded from the list of taxa identified as ${ }^{13} \mathrm{C}$ labelled in the rhizosphere test group (Additional Files 25 and 26).

\section{Polymerase chain reaction (PCR) and quantitative PCR assays}

Amplification of products by PCR was performed in $25 \mu \mathrm{L}$ reaction volumes using a BIORAD Tetrad 2 thermal cycler. The reaction mixture was $1 \times$ Master Mix (PCR Biosystems, UK), $0.4 \mu \mathrm{M}$ forward primer and $0.4 \mu \mathrm{M}$ reverse primer. PCR primers and amplification protocols used to screen for $16 \mathrm{~S}$ rRNA, mxaF, xoxF1-5 and $m d h 2$ genes are detailed in Additional File 27. PCR products were purified using NucleoSpin Gel and PCR clean-up columns (Macherey-Nagel, Germany) according to the manufacturer's instructions. The copy number of 16S rRNA, $m x a F$ and $x o x F 5$ genes in DNA and cDNA samples was estimated using quantitative PCR (qPCR) (Applied Biosystems Step one plus real-time PCR system, Thermo Fisher, MA, USA). The reaction mixture was BioLine Sensifast Hi Rox master mix, $0.4 \mu \mathrm{M}$ each primer and with the addition of bovine serum albumin $(0.2 \mu \mathrm{g})$. Standards were prepared using $x o x F 5$ and $m x a F$ 
PCR products amplified from DNA of Methylocella silvestris BL2, diluted to a copy number of $10^{8}$ to $10^{1}$ per microlitre. Three biological replicates from each environment were tested, each with three technical replicates. The efficiency of the amplification was $98 \%$ for $m x a F$ and $83 \%$ for xoxF5. A two-way ANOVA test was performed using the R package dplyr to test for significant differences between the test groups.

\section{Design of PCR primers to amplify $m d h 2$}

PCR primers were designed to amplify $m d h 2$ genes from DNA isolated from soils. The primers were based on conserved regions identified by aligning five $m d h 2$ sequences (Methylibium petroleiphilum PM1 AAEM01000000, Methyloversatilis universalis strain FAM5 EU548062, Methyloversatilis universalis EHg5 JN808865, Methyloversatilis discipulorum strain RZ18-153 EU548066, Methyloversatilis discipulorum strain FAM1 EU548063.1) using the MUSCLE algorithm in MEGA7 [75] and screening the alignment for a conserved region of 18-20 nucleotides, allowing for a maximum of three non-conserved bases. Specificity of the $m d h 2$ primers was tested by performing PCR using DNA extraction from two strains of methylotrophic bacteria, Methylibium sp. ROOT1272 (NZ_ LMDY00000000) and Methyloversatilis sp. soil isolate (MK795690), as positive controls and DNA from strains of bacteria that do not possess $m d h 2$ as negative controls (Methylobacillus sp. MM3 (NZ_LXTQ00000000), Methylovorus sp. MM2 (NZ_LXUF00000000), Hyphomicrobium sp. MMN) (MK795690). DNA extracted from unplanted soil, pea rhizosphere soil and methanolenriched pea rhizosphere soil was used as template to generate PCR amplicons of $m d h 2$. Mdh2-specific PCR products $(\sim 500 \mathrm{bp})$ were cloned using the Promega pGEM-T Easy vector system according to the manufacturer's instructions. Cloned PCR products were amplified using M13 primers (Additional File 27), and 20 clones from each library were screened by restriction fragment length polymorphism (RFLP). PCR products were digested using the restriction enzymes RsaI and AluI. RFLP profiles were analysed by gel electrophoresis using $2 \%(\mathrm{w} / \mathrm{v})$ agarose gels, and representative $m d h 2$ genes from different soil DNA samples were sequenced.

\section{Sequencing of $16 \mathrm{~S}$ rRNA and MDH genes}

$16 \mathrm{~S}$ rRNA gene amplicons were sequenced using Roche 454 (3000 reads) and Illumina MiSeq (20,000 reads) technology by Molecular Research LP (Shallowater, TX, USA). 16S rRNA gene amplicons produced using the 454 and Illumina platforms were processed by Molecular Research LP through their proprietary pipeline. Sequences were depleted of barcodes and primers then short sequences $<200 \mathrm{bp}$ were removed, together with sequences with ambiguous base calls and sequences with homopolymer runs exceeding $6 \mathrm{bp}$. Sequences were then denoised, and operational taxonomic units (OTUs) were defined as clustering at $97 \%$ similarity, following removal of singleton sequences and chimaeras [76-81]. Final OTUs were taxonomically classified using BLASTn against a curated database derived from GreenGenes, RDPII and NCBI (www.ncbi.nlm.nih.gov, http://rdp.cme. msu.edu) [82]. Beta diversity analysis was performed using the bioinformatics platform Qiime [83] to identify similarities between different the communities profiled by the sequencing of $16 \mathrm{~S}$ rRNA gene amplicons. Weighted and unweighted UniFrac analysis was performed on 16S rRNA gene amplicons produced from the unenriched, unplanted soils and pea and wheat rhizosphere soils in addition to the heavy and light fractions produced from the DNA-SIP experiments performed with ${ }^{13} \mathrm{C}$-methanol and ${ }^{13} \mathrm{CO}_{2}$.

Reads of functional (methanol dehydrogenase) genes sequenced using the 454 platform were analysed using a modified version of a published protocol [28]. SFF files were processed using Mothur [84] to convert the raw files into flowgrams, which were then translated to nucleotide sequences. USEARCH [85] was used for identification and removal of chimeric sequences. Sequences were clustered into OTUs using USEARCH [78], using similarity values of $80 \%$. OTUs were aligned using the MUSCLE algorithm against a database containing representative sequences from different clades of PQQ dehydrogenase. OTUs that clustered with each clade were re-aligned at the amino acid level using a database of sequences specific to that clade (Table 1). Phylogenetic trees were produced in MEGA7 [75] using the neighbour joining algorithm with bootstrap values of 500.454 sequencing of the xoxF3 amplicon produced data that was not of sufficient quality, and therefore, a clone library

Table 1 Number of OTUs in sequenced mxaF and xOXF amplicons produced from DNA extracted from soil

\begin{tabular}{llll}
\hline Gene & Soil environment & Sequencing platform & Number of OTUs \\
\hline XOxF1 & Unplanted & Roche 454 & 4 \\
xOxF2 & Unplanted & Sanger & 1 \\
xOxF3 & Unplanted & Sanger & 6 \\
xOxF5 & Unplanted & Roche 454 & 13 \\
xOxF5 & Pea rhizosphere & Roche 454 & 19 \\
xOxF5 & Wheat rhizosphere & Roche 454 & 14 \\
mxaF & Unplanted & Roche 454 & 4 \\
mxaF & Pea rhizosphere & Roche 454 & 4 \\
\hline Amplicons & &
\end{tabular}

Amplicons were produced from DNA samples from unplanted soil, pea rhizosphere soil and wheat rhizosphere soil and analysed by either 454 amplicon sequencing or Sanger sequencing. OTUs were produced using an $80 \%$ identity clustering threshold 
of 100 clones was made from the $x o x F 3$ PCR amplicon obtained from DNA extracted from unplanted soil. This clone library was constructed and screened via RFLP as described above.

\section{Metagenome sequencing and analysis}

DNA from the ${ }^{13} \mathrm{C}$-heavy fractions of the methanol SIP experiment was pooled, quantified and sequenced by the Centre for Genomic Research at the University of Liverpool. Sequencing was performed using paired-end sequencing $(2 \times 150 \mathrm{bp})$ on an Illumina HiSeq 4000. Short sequences and sequences of poor quality were excluded from the files using the program Trimmomatic $(0.36)$ [86], and the quality of the metagenomes was assessed using QUAST, including the MetaQUAST expansion (5.0.0) (Table 2) [87].

Trimmed reads were analysed using Metaphlan 2 (2.0) [43]. Reads were assembled using Megahit (1.1.2) [88] and annotated using myRast (35) [89]. The metagenomes were screened for genes of interest using protein sequences of confirmed function using tblastn in BioEdit [90]. For quantification of the methanol dehydrogenase genes, the assembled and unassembled reads were converted to blast databases and screened using the blastn algorithm and representative sequences for each clade of methanol dehydrogenase-encoding gene ( $x o x F 1, x o x F 2$, $x o x F 3, x o x F 4, x o x F 5, m x a F, m d h 2)$. Appropriate stringencies for the BLAST searches were determined by selecting the lowest $e$ value that did not yield sequences of the incorrect clade (Additional File 11). Abundance values were normalised to gene length or gene length and read number for the assembled and unassembled metagenome reads respectively. The percentage of bacteria represented in the unassembled read data that

Table 2 Statistics of metagenomes assembled from the heavy fraction of methanol-enriched rhizosphere and unplanted soils

\begin{tabular}{llll}
\hline & \multicolumn{3}{l}{ Metagenome } \\
\cline { 2 - 4 } & Pea & Unplanted & Wheat \\
\hline \# contigs ( $\geq 0$ bp) & 1151414 & 1251579 & 981758 \\
\# contigs ( $\geq 1000$ bp) & 195697 & 192658 & 106074 \\
Total length ( $\geq 0$ bp) & 934363676 & 922084398 & 616537133 \\
Total length ( $\geq 1000$ bp) & 456772046 & 392066999 & 186491273 \\
Total length & 717825918 & 682211092 & 415542434 \\
GC (\%) & 63.9 & 64.58 & 65.92 \\
N50 & 1397 & 1168 & 916 \\
L50 $^{2}$ & 112046 & 145393 & 128331 \\
\hline
\end{tabular}

The quality of metagenomes were analysed using the program QUAST. The metagenomes were produced by shotgun sequencing of ${ }^{13} \mathrm{C}$-labelled DNA extracted from methanol-enriched wheat rhizosphere soil (wheat), pea plant rhizosphere soil (pea) and unplanted soil (CF) incubated from ${ }^{13} \mathrm{C}$-labelled methanol for 17 days

${ }^{1} \mathrm{~N} 50$ is the length for which the collection of all contigs of that length or longer covers at least half an assembly

${ }^{2} L 50$ is the number of contigs equal to or longer than N50 possess a methanol dehydrogenase was calculated from the abundance of the methanol dehydrogenase genes divided by the abundance of the housekeeping gene $r e c A$. The sequences with the highest sequence identity to the identified methanol dehydrogenase sequences from the assembled metagenomes were identified using the blastn algorithm against the NCBI database (Additional File 16).

Contigs were binned into metagenome-assembled genomes (MAGs) using MetaBAT (2.21.1) with the "superspecific" and "veryspecific" algorithms [91]. The completeness, contamination and heterogeneity of these MAGs were assessed using the program CheckM (1.0.13) [92]. The MAGs of sufficient quality binned from the metagenomes (completeness score above $70 \%$ and contamination below $10 \%$, meeting currently accepted criteria for medium to high quality MAGs [44]) were also screened for genes of interest using protein sequences of confirmed function using tblastn in BioEdit [90]. Average nucleotide identity (ANI) calculations were performed to assess the similarity of the MAGs Methylophilales ss01 and ss29 to the genomes Methylovorus sp. MM2 (NZ_ LXUF00000000) and Methylobacillus sp. MM3 (NZ LXTQ00000000) [84].

\section{Screening of the genomes of members of the Comamonadaceae for xox $F$ genes}

Three hundred fifteen genomes of members of the Comamonadaceae were downloaded from NCBI GenBank. Genomes were screened for the presence of methanol dehydrogenase-encoding genes using local Blast searches (tblastn), using the xoxF5 sequence of Variovorax paradoxus S110 (NZ_ARNA00000000.1) as query in BioEdit [83].

\section{Supplementary information}

Supplementary information accompanies this paper at https://doi.org/10. 1186/s40168-020-00801-4.

Additional file 1. 165 rRNA gene profiles of bacteria in unplanted, pea rhizosphere and wheat rhizosphere soils.

Additional file 2. Relative abundance (\%) of methylotrophic genera in 16S rRNA gene profile of soils.

Additional file 3. Phylogeny of mxaF sequences retrieved from pea plant rhizosphere and unplanted soil.

Additional file 4. Phylogeny of xoxF5 sequences retrieved from pea plant rhizosphere, wheat plant rhizosphere and unplanted soil.

Additional file 5. Phylogeny and relative abundance of xoxF1 sequences retrieved from soil.

Additional file 6. Phylogeny and relative abundance of xoxF3 sequences retrieved from soil.

Additional file 7. Phylogeny of a xoxF2 sequence retrieved from soil. Additional file 8. Relative abundance of methanol dehydrogenase encoding genes in unplanted and rhizosphere soils. 
Additional file 9. Diversity indices of the communities in the heavy fraction of methanolenriched rhizosphere and unplanted soils.

Additional file 10. Relative abundance of $16 \mathrm{~s}$ rRNA gene.

Additional file 11. Abundance of unique methanol dehydrogenase encoding genes sequences identified in the metagenomes asssembled from methanol-enriched soils.

Additional file 12. Diversity of xoxF1 gene sequences retrieved from the heavy fractions of soils enriched with 13C methanol.

Additional file 13. Diversity of xoxF4 gene sequences retrieved from the heavy fractions of soils enriched with 13C methanol.

Additional file 14. Diversity of xoxF5 gene sequences retrieved from the heavy fractions of soils enriched with $13 \mathrm{C}$ methanol.

Additional file 15. Diversity of mxaF gene sequences retrieved from the heavy fractions of soils enriched with $13 \mathrm{C}$ methanol.

Additional file 16. BLAST scoring details of unique mdh2 sequences identified in metagenomes produced from methanol enriched soils.

Additional file 17. Details of metagenomes assembled genomes (MAGS) binned from metagenomes assembled from methanol-enriched soils

Additional file 18. Taxonomy of MAGS and the identification of funtional genes involved in C1, nitrogen and sulfur cycling.

Additional file 19. Phylogeny of a xoxF3 sequence retrieved from metagenome assembled genome Methylotenera ss03.

Additional file 20. Putative and confirmed methylotrophs identified in the pea rhizosphere using multiple approaches.

Additional file 21. Putative and confirmed methylotrophs identified in the wheat rhizosphere using multiple approaches.

Additional file 22. Putative and confirmed methylotrophs identified in the unplanted soil using multiple approaches.

Additional file 23. NMDS plot showing the unweighted unifrac analysis of 165 rRNA gene amplicons produced from DNA extracted from unenriched soils, soils enriched with methanol and rhizosphere soils supplemented with 1000 ppm and 350 ppm carbon dioxide.

Additional file 24. Workflow schematic of the DNA-SIP with methanol, the DNA SIP with carbon dioxide and the sequencing and quantification of the methanol dehydrogenase genes and $16 \mathrm{~S}$ rRNA gene from the soil habitats.

Additional file 25. Relative abundance of genera detected as labelled in 165 rRNA gene profiles of the 350 ppmv supplied test groups.

Additional file 26. Relative abundance of genera detected as labelled in 165 rRNA gene profiles of the 1000 ppmv supplied test groups.

Additional file 27. PCR primers used in this study.

\section{Acknowledgements}

Not applicable

\section{Authors' contributions}

JCM, ATC and MCM designed the series of experiments. MCM and JP collected the samples. MCM performed the experiments. JP and MCM performed the bioinformatics. All authors contributed to the development of the manuscript. All authors read and approved the final manuscript.

\section{Funding}

This work was supported by the Norwich Research Park BBSRC Doctoral Training Program, the Earth and Life Systems Alliance (ELSA) at the University of East Anglia, NERC Independent Research Fellowship NE/L010771/1 and Leverhulme Early Career Fellowship ECF-2016-626.

\section{Availability of data and materials}

Amplicon sequence data generated in this study were deposited to sequence read archives (SRA) under project numbers PRJNA533080, PRJNA533036 and PRJNA533035. Metagenome data was deposited to the SRA under project number PRJNA533040. MAGs were uploaded to the SRA under project number PRJNA533039. Clone library sequence data were deposited to NCBI GenBank under accession numbers MN207223-MN207231.

Ethics approval and consent to participate

Not applicable

Consent for publication

Not applicable

\section{Competing interests}

The authors declare that they have no competing interests

\section{Author details}

${ }^{1}$ School of Environmental Sciences, University of East Anglia, Norwich Research Park, Norwich NR4 7TJ, UK. ${ }^{2}$ AstrobiologyOU, Faculty of Science, Technology, Engineering and Mathematics, The Open University, Milton Keynes, Buckinghamshire MK7 6AA, UK. ${ }^{3}$ The Lyell Centre, School of Energy, Geoscience, Infrastructure and Society, Heriot-Watt University, Research Avenue South, Edinburgh EH14 4AP, UK. ${ }^{4}$ School of Biological Sciences, University of East Anglia, Norwich Research Park, Norwich NR4 7TJ, UK.

Received: 31 July 2019 Accepted: 10 February 2020

Published online: 10 March 2020

\section{References}

1. Marschner B. Mineral nutrition in higher plants. 2nd ed. London: Academic Press; 1995

2. Haichar FEZ, Marol C, Berge O, Rangel-Castro Jl, Prosser JI, Balesdent J, et al. Plant host habitat and root exudates shape soil bacterial community structure. ISME J. 2008:2:1221-30.

3. Dennis PG, Miller AJ, Hirsch PR. Are root exudates more important than other sources of rhizodeposits in structuring rhizosphere bacterial communities? FEMS Microbiol Ecol. 2010;72:313-27.

4. Steeghs M, Bais HP, De Gouw J, Goldan P, Kuster W, Northway M, et al. Proton-transfer-reaction mass spectrometry as a new tool for real time analysis of root-secreted volatile organic compounds in Arabidopsis 1. Plant Physiol. 2004;135:47-58.

5. Galbally IE, Kirstine W. The production of methanol by flowering plants and the global cycle of methanol. J Atmos Chem. 2002;43:195-229.

6. Oikawa PY, Giebel BM, Sternberg LDSLO, Li L, Timko MP, Swart PK, et al. Leaf and root pectin methylesterase activity and ${ }^{13} \mathrm{C} /{ }^{12} \mathrm{C}$ stable isotopic ratio measurements of methanol emissions give insight into methanol production in Lycopersicon esculentum. New Phytol. 2011;191:1031-40.

7. Kolb S. Aerobic methanol-oxidizing bacteria in soil. FEMS Microbiol Lett. 2009:300:1-10

8. Mcdonald IR, Murrell JC. The methanol dehydrogenase structural gene $m \times a F$ and its use as a functional gene probe for methanotrophs and methylotrophs. Appl Environ Microbiol. 1997;63:3218-24.

9. Neufeld JD, Chen Y, Dumont MG, Murrell JC. Marine methylotrophs revealed by stable-isotope probing, multiple displacement amplification and metagenomics. Environ Microbiol. 2008;10:1526-35.

10. Radajewski S, Ineson P, Parekh NR, Murrell JC. Stable-isotope probing as a tool in microbial ecology. Nature. 2000;403:646-9.

11. Madhaiyan M, Poonguzhali S, Lee J-S, Lee KC, Sundaram S. Flavobacterium glycines sp. nov., a facultative methylotroph isolated from the rhizosphere of soybean. Int J Syst Evol Microbiol. 2010;60:2187-92.

12. Lundberg DS, Lebeis SL, Paredes SH, Yourstone S, Gehring J, Malfatti S, et al. Defining the core Arabidopsis thaliana root microbiome. Nature. 2012:488: 86-90.

13. Turner TR, Ramakrishnan K, Walshaw J, Heavens D, Alston M, Swarbreck D, et al. Comparative metatranscriptomics reveals kingdom level changes in the rhizosphere microbiome of plants. ISME J. 2013;7:2248-58.

14. Knief C, Delmotte N, Chaffron S, Stark M, Innerebner G, Wassmann R, et al. Metaproteogenomic analysis of microbial communities in the phyllosphere and rhizosphere of rice. ISME J. 2012:6:1378-90.

15. Tsurumaru H. Metagenomic analysis of the bacterial community associated with the taproot of sugar beet. Microbes Environ. 2015:30:63-9.

16. Butterfield CN, Li Z, Andeer PF, Spaulding S, Thomas BC, Singh A, et al. Proteogenomic analyses indicate bacterial methylotrophy and archaeal heterotrophy are prevalent below the grass root zone. PeerJ. 2016:1-28. 
17. Li Z, Yao Q, Guo X, Crits-Christoph A, Mayes MA, Hervey WJ IV, et al. Genome-resolved proteomic stable isotope probing of soil microbial communities using ${ }^{13} \mathrm{CO}_{2}$ and ${ }^{13} \mathrm{C}$-methanol. Front Microbiol. 2019;10:2706.

18. Stacheter A, Noll M, Lee CK, Selzer M, Glowik B, Ebertsch L, et al. Methanol oxidation by temperate soils and environmental determinants of associated methylotrophs. ISME J. 2013;7:1051-64.

19. Kuzyakov Y, Domanski G. Carbon input by plants into the soil. Rev J Plant Nutr Soil Sci. 2000;163:421-31.

20. Morris CJ, Biville F, Turlin E, Lee E, Ellermann K, Fan WH, et al. Isolation, phenotypic characterization, and complementation analysis of mutants of Methylobacterium extorquens AM1 unable to synthesize pyrroloquinoline quinone and sequences of pqqD, pqqG, and pqqC. J Bacteriol. 1994;176: 1746-55.

21. Anthony $C$, Williams $P$. The structure and mechanism of methanol dehydrogenase. Biochim Biophys Acta. 1647;2003:18-23.

22. Zhang M. Promoters and transcripts for genes involved in methanol oxidation in Methylobacterium extorquens AM1. Microbiology. 2003;149: 1033-40.

23. Keltjens JT, Pol A, Reimann J. PQQ-dependent methanol dehydrogenases: rare-earth elements make a difference. Appl Microbiol Biotechnol. 2014;98: 6163-83.

24. Chistoserdova L. Modularity of methylotrophy, revisited. Environ Microbiol. 2011;13:2603-22

25. Kalyuzhnaya MG, Hristova KR, Lidstrom ME, Chistoserdova L. Characterization of a novel methanol dehydrogenase in representatives of Burkholderiales: implications for environmental detection of methylotrophy and evidence for convergent evolution. J Bacteriol. 2008;190:3817-23.

26. Morawe M, Hoeke H, Wissenbach DK, Lentendu G, Wubet T, Kröber E, et al. Acidotolerant bacteria and fungi as a sink of methanol-derived carbon in a deciduous forest soil. Front Microbiol. 2017:8:1-18.

27. Horz H-P, Tchawa Y, Liesack W. Detection of methanotroph diversity on roots of submerged rice plants by molecular retrieval of $p m o A, m m o X$, mxaF, and $16 \mathrm{~S}$ rRNA and ribosomal DNA, including pmoA-based terminal restriction fragment length polymorphism profiling. Appl Environ Microbiol. 2001;67:67-72

28. Taubert M, Grob C, Howat AM, Burns OJ, Dixon JL, Chen Y, et al. XoxF encoding an alternative methanol dehydrogenase is widespread in coastal marine environments. Environ Microbiol. 2015;17:3937-48.

29. Griffiths RI, Manefield M, Ostle N, McNamara N, O'Donnell AG, Bailey MJ, et al. ${ }^{13} \mathrm{CO}_{2}$ pulse labelling of plants in tandem with stable isotope probing: methodological considerations for examining microbial function in the rhizosphere. J Microbiol Methods. 2004;58:119-29.

30. Iguchi H, Yurimoto H, Sakai Y. Interactions of methylotrophs with plants and other heterotrophic bacteria. Microorganisms. 2015;3:137-51.

31. Kalyuzhnaya MG, De Marco P, Bowerman S, Pacheco CC, Lara JC, Lidstrom $M E$, et al. Methyloversatilis universalis gen. nov., sp. nov., a novel taxon within the Betaproteobacteria represented by three methylotrophic isolates. Int J Syst Evol Microbiol. 2006;56:2517-22.

32. Ciencias D, Universitaria C. Culturable facultative methylotrophic bacteria from the cactus Neobuxbaumia macrocephala possess the locus XoxF and consume methanol in the presence of $\mathrm{Ce}^{3+}$ and $\mathrm{Ca}^{2+}$. Microbes Environ. 2017;32:244-51.

33. Quayle JR, Pfennig N. Utilization of methanol by Rhodospirillaceae. Arch Microbiol. 1975;102:193-8.

34. Moore RL. The biology of Hyphomicrobium and other prosthecate, budding bacteria. Annu Rev Microbiol. 1981:567-94.

35. Sennett SH, Pomponi SA, Willenz P, Mccarthy PJ. Identification of the bacterial symbiont Entotheonella sp. in the mesohyl of the marine sponge Discodermia sp. ISME J. 2008;4206:335-9.

36. Wilson MC, Mori T, Rückert C, Uria AR, Helf MJ, Takada K, et al. An environmental bacterial taxon with a large and distinct metabolic repertoire. Nature. 2014;506:58-62.

37. Dziewit L, Czarnecki J, Prochwicz E, Wibberg D, Schulter A, Puhler A, et al. Genome-guided insight into the methylotrophy of Paracoccus aminophilus JCM 7686. Front Microbiol. 2015;6:1-13.

38. Fitriyanto NA, Fushimi M, Matsunaga M, Pertiwiningrum A, Iwama T, Kawai K. Molecular structure and gene analysis of $\mathrm{Ce}^{3+}$-induced methanol dehydrogenase of Bradyrhizobium sp. MAFF211645. J Biosci Bioeng. 2011; 111:613-7.

39. Huang J, Yu Z, Chistoserdova L. Lanthanide-dependent methanol dehydrogenases of XoxF4 and XoxF5 clades are differentially distributed among methylotrophic bacteria and they reveal different biochemical properties. Front Microbiol. 2018;9:1-13.

40. Sutherland IW. Polysaccharides produced by Cystobactev, Archangium, Sorangium and Stigmatella species. J Gen Appl Microbiol. 1978:1-5.

41. Cho JC, Vergin KL, Morris RM, Giovannoni SJ. Lentisphaera araneosa gen. nov., sp. nov, a transparent exopolymer producing marine bacterium, and the description of a novel bacterial phylum, Lentisphaerae. Environ Microbiol. 2004;6:611-21.

42. Chin KJ, Liesack W, Janssen PH. Opitutus terrae gen. nov., sp. nov., to accommodate novel strains of the division "Verrucomicrobia" isolated from rice paddy soil. Int J Syst Evol Microbiol. 2001;51:1965-8.

43. Segata N, Waldron L, Ballarini A, Narasimhan V, Jousson O, Huttenhower C. Metagenomic microbial community profiling using unique clade- specific marker genes. Nat Methods. 2012:1-7.

44. Bowers RM, Kyrpides NC, Stepanauskas R, Harmon-smith M, Doud D, Jarett J, et al. Minimum information about a single amplified genome (MISAG) and a metagenome-assembled genome (MIMAG) of bacteria and archaea. Nat Biotechnol. 2017;35:725-31.

45. Marx CJ, Chistoserdova L, Lidstrom ME. Formaldehyde-detoxifying role of the tetrahydromethanopterin-linked pathway in Methylobacterium extorquens AM1. J Bacteriol. 2003:185:7160-8.

46. Chen Y, McAleer KL, Colin MJ. Monomethylamine as a nitrogen source for a nonmethylotrophic bacterium, Agrobacterium tumefaciens. Appl Environ Microbiol. 2010;76:4102-4.

47. Chistoserdova L, Crowther GJ, Vorholt JA, Skovran E, Portais J, Lidstrom ME. Identification of a fourth formate dehydrogenase in Methylobacterium extorquens AM1 and confirmation of the essential role of formate oxidation in methylotrophy. J Bacteriol 2007;189:9076-90781.

48. Chistoserdova L, Laukel M, Portais J, Vorholt JA, Lidstrom ME. Multiple formate dehydrogenase enzymes in the facultative methylotroph Methylobacterium extorquens AM1 are dispensable for growth on methanol. J Bacteriol. 2004;186:22-8.

49. Laukel M, Chistoserdova L, Lidstrom ME, Vorholt JA. The tungstencontaining formate dehydrogenase from Methylobacterium extorquens AM1: purification and properties. Eur J Biochem. 2003;333:325-33.

50. Macey MC, Pratscher J, Crombie A, Murrell JC. Draft genome sequences of obligate methylotrophs Methylovorus sp. strain MM2 and Methylobacillus sp. strain MM3, isolated from grassland soil. Microbiol Resour Announc. 2018;7:1-2.

51. Feng S, Tan CH, Constancias F, Kohli GS, Cohen Y, Rice SA. Predation by Bdellovibrio bacteriovorus significantly reduces viability and alters the microbial community composition of activated sludge flocs and granules. FEMS Microbiol Ecol. 2017. p. 1-12.

52. Boden R, Thomas E, Savani P, Kelly DP, Wood AP. Novel methylotrophic bacteria isolated from the River Thames (London, UK). Environ Microbiol. 2008;10:3225-36.

53. Harms N, van Spanning RJM. C1 metabolism in Paracoccus denitrificans: genetics of Paracoccus denitrificans. J Bioenerg Biomembr. 1991;23:187-210.

54. Anesti V, McDonald IR, Ramaswamy M, Wade WG, Kelly DP, Wood AP. Isolation and molecular detection of methylotrophic bacteria occurring in the human mouth. Environ Microbiol. 2005;7:1227-38.

55. Drigo B, Pijl AS, Duyts H, Kielak AM, Gamper HA, Houtekamer MJ. Shifting carbon flow from roots into associated microbial communities in response to elevated atmospheric $\mathrm{CO}_{2}$. Proc Natl Acad Sci. 2010;107:10938-42.

56. Noar JD, Buckley DH. Ideonella azotifigens sp. nov., an aerobic diazotroph of the Betaproteobacteria isolated from grass rhizosphere soil, and emended description of the genus Ideonella. Int J Syst Evol Microbiol. 2009;59:1941-6.

57. Schmalenberger A, Hodge S, Bryant A, Hawkesford M, Singh B, Kertesz M. The role of Variovorax and other Comamonadaceae in sulfur transformations by microbial wheat fertilization regimes. FEMS Microbiol Ecol. 2007. p. 1-38.

58. Agafonova NV, Doronina NV, Kaparullina EN, Fedorov DN, Gafarov AB, Sazonova Ol, et al. A novel Delftia plant symbiont capable of autotrophic methylotrophy. Microbiology. 2017;86:96-105.

59. Kalyuzhnaya MG, Lapidus A, Ivanova N, Copeland AC, McHardy AC, Szeto E, et al. High-resolution metagenomics targets specific functional types in complex microbial communities. Nat Biotechnol. 2008;26:1029-34.

60. Durán P, Thiergart T, Garrido-Oter R, Agler M, Kemen E, Schulze-Lefert P, et al. Microbial interkingdom interactions in roots promote Arabidopsis survival. Cell. 2018:175, 973-983.e14.

61. Satola B, Wübbeler JH, Steinbüchel A. Metabolic characteristics of the species Variovorax paradoxus. Appl Microbiol Biotechnol. 2013;97:541-60. 
62. Videira SS, De Araujo JLS, Da Silva RL, Baldani VLD, Baldani Jl. Occurrence and diversity of nitrogen-fixing Sphingomonas bacteria associated with rice plants grown in Brazil. FEMS Microbiol Lett. 2009;293:11-9.

63. Gremion F, Chatzinotas A, Harms H. Comparative $16 \mathrm{~S}$ rDNA and $16 \mathrm{~S}$ rRNA sequence analysis indicates that Actinobacteria might be a dominant part of the metabolically active bacteria in heavy metal-contaminated bulk and rhizosphere soil. Environ Microbiol. 2003;5:896-907.

64. Ai C, Liang G, Sun J, Wang X, He P, Zhou W, et al. Reduced dependence of rhizosphere microbiome on plant-derived carbon in 32-year long-term inorganic and organic fertilized soils. Soil Biol Biochem. Elsevier Ltd; 2015; 80:70-78.

65. Hernández M, Dumont MG, Yuan Q, Conrad R. Different bacterial populations associated with the roots and rhizosphere of rice incorporate plant-derived carbon. Appl Environ Microbiol. 2015;81:2244-53.

66. Delmotte N, Knief C, Chaffron S, Innerebner G, Roschitzki B, Schlapbach R, et al. Community proteogenomics reveals insights into the physiology of phyllosphere bacteria. Proc Natl Acad Sci. 2009;106:16428-33.

67. Knief C, Frances L, Cantet F, Vorholt JA. Cultivation-independent characterization of Methylobacterium populations in the plant phyllosphere by automated ribosomal intergenic spacer analysis. Appl Environ Microbiol. 2008;74:2218-28.

68. Remus-emsermann MNP, Lücker S, Müller DB, Potthoff E, Daims H, Vorholt JA. Spatial distribution analyses of natural phyllosphere-colonizing bacteria on Arabidopsis thaliana revealed by fluorescence in situ hybridization. Environ Microbiol. 2014;16:2329-40.

69. Abanda-Nkpwatt D, Müsch M, Tschiersch J, Boettner M, Schwab W. Molecular interaction between Methylobacterium extorquens and seedlings: growth promotion, methanol consumption, and localization of the methanol emission site. J Exp Bot. 2006;57:4025-32.

70. Mora M, Perras A, Alekhova TA, Wink L, Krause R, Aleksandrova A, et al. Resilient microorganisms in dust samples of the International Space Station - survival of the adaptation specialists. Microbiome. 2016. p. 1-21.

71. Chaparro JM, Badri D V, Vivanco JM. Rhizosphere microbiome assemblage is affected by plant development. ISME J. 2013;8(4):1-14

72. Griffiths RI, Whiteley AS, Donnell AGO, Bailey MJ. Rapid method for coextraction of DNA and RNA from natural environments for analysis of ribosomal DNA- and rRNA-based microbial community composition. Appl Environ Microbiol. 2000;66:5488-91.

73. Dunfield PF, Khmelenina VN, Suzina NE, Trotsenko YA, Dedysh SN. Methylocella silvestris sp. nov., a novel methanotroph isolated from an acidic forest cambisol. Int J Syst Evol Microbiol. 2003;53:1231-9.

74. Neufeld JD, Vohra J, Dumont MG, Lueders T, Manefield M, Friedrich MW, et al. DNA stable-isotope probing. Nat Protoc. 2007;2:860-6.

75. Kumar S, Stecher G, Tamura K. MEGA7: Molecular Evolutionary Genetics Analysis Version 7.0 for bigger datasets. Mol Biol Evol. 2016;33:1870-4.

76. Dowd SE, Callaway TR, Wolcott RD, Sun Y, McKeehan T, Hagevoort RG, et al. Evaluation of the bacterial diversity in the feces of cattle using $16 \mathrm{~S}$ rDNA bacterial tag-encoded FLX amplicon pyrosequencing (bTEFAP). BMC Microbiol. 2008:8:1-8.

77. Dowd SE, Sun Y, Wolcott RD, Domingo A, Carroll JA. Bacterial tag-encoded FLX amplicon pyrosequencing (bTEFAP) for microbiome studies: bacterial diversity in the lleum of newly weaned salmonella-infected pigs. Foodborne Pathog Dis. 2008;5:459-72.

78. Edgar RC. Search and clustering orders of magnitude faster than BLAST. Bioinformatics. 2010;26:2460-1.

79. Eren AM, Zozaya M, Taylor CM, Dowd SE, Martin DH, Ferris MJ. Exploring the diversity of Gardnerella vaginalis in the genitourinary tract microbiota of monogamous couples through subtle nucleotide variation. PLoS One. 2011;6.

80. Swanson KS, Dowd SE, Suchodolski JS, Middelbos IS, Vester BM, Barry KA, et al. Phylogenetic and gene-centric metagenomics of the canine intestinal microbiome reveals similarities with humans and mice. ISME J. 2011;5:639-49.

81. Capone KA, Dowd SE, Stamatas GN, Nikolovski J. Diversity of the human skin microbiome early in life. J Invest Dermatol. 2011;131:2026-32.

82. DeSantis TZ, Hugenholtz P, Larsen N, Rojas M, Brodie EL, Keller K, et al. Greengenes, a chimera-checked $16 \mathrm{~S}$ rRNA gene database and workbench compatible with ARB. Appl Environ Microbiol. 2006;72:5069-72.

83. Caporaso JG, Kuczynski J, Stombaugh J, Bittinger K, Bushman FD, Costello EK, et al. Correspondence QIIME allows analysis of high- throughput community sequencing data intensity normalization improves color calling in SOLiD sequencing. Nat Methods. 2010;7:335-6.
84. Schloss PD, Westcott SL, Ryabin T, Hall JR, Hartmann M, Hollister EB, et al. Introducing mothur: open-source, platform-independent, communitysupported software for describing and comparing microbial communities. Nucleic Acids Res. 2009;75:7537-41.

85. Edgar RC, Haas BJ, Clemente JC, Quince C, Knight R. UCHIME improves sensitivity and speed of chimera detection. Bioinformatics. 2011;27:2194-200.

86. Bolger AM, Lohse M, Usadel B. Trimmomatic: a flexible trimmer for Illumina sequence data. Bioinformatics. 2014;30:2114-20.

87. Gurevich A, Saveliev V, Vyahhi N, Tesler G. QUAST: quality assessment tool for genome assemblies. Bioinformatics. 2013;29:1072-5.

88. Li D, Liu C, Luo R, Sadakane K, Lam T. Sequence analysis MEGAHIT: an ultrafast single-node solution for large and complex metagenomics assembly via succinct de Bruijn graph. Bioinformatics. 2015;31:1674-6.

89. da Rocha UN, van Overbeek $L$, van Elsas JD. Exploration of hithertouncultured bacteria from the rhizosphere. FEMS Microbiol Ecol. 2009;69: 313-28.

90. Kang DD, Froula J, Egan R, Wang Z. MetaBAT, an efficient tool for accurately reconstructing single genomes from complex microbial communities. PeerJ. 2015:3:e1165.

91. Parks DH, Imelfort M, Skennerton CT, Hugenholtz P, Tyson GW. CheckM: assessing the quality of microbial genomes recovered from isolates, single cells, and metagenomes. Genome Res. 2015;25:1043-55.

92. Hall AT. BioEdit: an important software for molecular biology. GERF Bull Biosci. 2011;2:60-1.

\section{Publisher's Note}

Springer Nature remains neutral with regard to jurisdictional claims in published maps and institutional affiliations.
Ready to submit your research? Choose BMC and benefit from:

- fast, convenient online submission

- thorough peer review by experienced researchers in your field

- rapid publication on acceptance

- support for research data, including large and complex data types

- gold Open Access which fosters wider collaboration and increased citations

- maximum visibility for your research: over $100 \mathrm{M}$ website views per year

At BMC, research is always in progress.

Learn more biomedcentral.com/submissions 